\title{
Eco-Friendly Coagulant versus Industrially Used Coagulants: Identification of Their Coagulation Performance, Mechanism and Optimization in Water Treatment Process
}

\author{
Nadiah Khairul Zaman 1미, Rosiah Rohani ${ }^{1,2, *} \mathbb{C}$, Izzati Izni Yusoff ${ }^{1}$, Muhammad Azraei Kamsol ${ }^{1}$, \\ Siti Aishah Basiron ${ }^{1,3}$ and Aina Izzati Abd. Rashid ${ }^{4}$ \\ 1 Department of Chemical \& Process Engineering, Faculty of Engineering \& Built Environment, Universiti \\ Kebangsaan Malaysia, UKM, Bangi 43600, Malaysia; nadiahkz@gmail.com (N.K.Z.); \\ nurul.izzati.izni@gmail.com (I.I.Y.); muhd.azraei24@gmail.com (M.A.K.); aishah@samb.com.my (S.A.B.) \\ 2 Research Centre for Sustainable Process Technology, Faculty of Engineering \& Built Environment, Universiti \\ Kebangsaan Malaysia, UKM, Bangi 43600, Malaysia \\ 3 Makmal Pusat, Syarikat Air Melaka Berhad, Jalan Padang Keladi, Durian Tunggal, Melaka 76100, Malaysia \\ 4 Department of Civil Engineering, Faculty of Engineering \& Built Environment, Universiti Kebangsaan \\ Malaysia, UKM, Bangi 43600, Malaysia; ainaagibs@gmail.com \\ * Correspondence: rosiah@ukm.edu.my; Tel.: +60-389-216-408; Fax: +60-389-118-345
}

Citation: Khairul Zaman, N.; Rohani, R.; Izni Yusoff, I.; Kamsol, M.A.; Basiron, S.A.; Abd. Rashid, A.I. Eco-Friendly Coagulant versus Industrially Used Coagulants: Identification of Their Coagulation Performance, Mechanism and Optimization in Water Treatment Process. Int. J. Environ. Res. Public Health 2021, 18, 9164. https://doi.org/ 10.3390/ijerph18179164

Academic Editor: Panagiotis Karanis

Received: 15 July 2021

Accepted: 23 August 2021

Published: 31 August 2021

Publisher's Note: MDPI stays neutral with regard to jurisdictional claims in published maps and institutional affiliations.

Copyright: (c) 2021 by the authors. Licensee MDPI, Basel, Switzerland. This article is an open access article distributed under the terms and conditions of the Creative Commons Attribution (CC BY) license (https:/ / creativecommons.org/licenses/by/ $4.0 /)$.

\begin{abstract}
The evaluation of complex organic and inorganic coagulant's performances and their relationships could compromise the surface water treatment process time and its efficiency. In this work, process optimization was investigated by comparing an eco-friendly chitosan with the industrially used coagulants namely aluminum sulfate (alum), polyaluminum chloride (PAC), and aluminum chlorohydrate $(\mathrm{ACH})$ in compliance with national drinking water standards. To treat various water samples from different treatment plants with turbidity and $\mathrm{pH}$ ranges from 20-826.3 NTU and 5.21-6.80, respectively, 5-20 mg/L coagulant dosages were varied in the presence of aluminum, ferum, and manganese. Among all, $10 \mathrm{mg} / \mathrm{L}$ of the respective $\mathrm{ACH}$ and chitosan demonstrated $97 \%$ and $99 \%$ turbidity removal in addition to the removal of the metals that complies with the referred standard. However, chitosan owes fewer sensitive responses (turbidity and residual metal) with the change in its input factors (dosage and $\mathrm{pH}$ ), especially in acidic conditions. This finding suggested its beneficial role to be used under the non-critical dosage monitoring. Meanwhile, ACH was found to perform better than chitosan only at $\mathrm{pH}>7.4$ with half dosage required. In summary, chitosan and $\mathrm{ACH}$ could perform equally at a different set of optimum conditions. This optimization study offers precise selections of coagulants for a practical water treatment operation.
\end{abstract}

Keywords: aluminum coagulant; chitosan; metal removal; optimization; water treatment plant

\section{Introduction}

Worldwide, the water crisis has become a serious issue as the global population increases and climate changes worsen. By 2030, it has been estimated that 700 million people worldwide could experience an intense water scarcity [1,2]. To overcome the challenges, rapid advancement in water treatment technology is necessary to deliver protected and potable drinking water readily. Drinking water is usually treated via different techniques depending on the quality of the raw water, the degree of contamination, and regulations for public health safeguarding [3]. Among all water treatment technologies, coagulation and flocculation have been an essential part of drinking water and wastewater treatment processes for decades [3,4].

To date, research and development of coagulants have been carried out intensively to improve and establish coagulants with certain properties such as being less hazardous to the environment, having high stability, and being resilient to various process conditions so as to allow maximum coagulation performances [5]. This resulted in immense 
exploration and comparison between coagulants from both inorganic and organic, which include the traditional industrially used coagulant of aluminum sulfate (alum) that has been the most widely used coagulant, due to its low cost and abundant availability [6]. Other industrially used coagulants are the pre-hydrolyzed inorganic coagulants, namely polyaluminum chloride (PAC) [7], aluminum chlorohydrate (ACH) [7], and ferric chloride (the iron form coagulant) [8,9], which pose inherent advantages such as simplicity in their application and properties, and their ease to control during the manufacturing process [10]. Apart from the inorganic coagulants, organic coagulants such as chitosan have also attracted much attention due to their low cost and environmentally friendly features. Depending on the contaminants treated, the sludge produced from organic coagulant is usually biodegradable and does not create harmful chemical residue effluents [11,12]. The utilization of organic coagulants was also reported to reduce any potential health hazards related to the increase in $\mathrm{Al}$ concentration in drinking water that could have possibly occurred from the utilization of inorganic Al-based coagulants. A study reported a potential link between the neurotoxicity sourced from aluminum and its pathogenesis to Alzheimer's disease [13]. The inorganic coagulants could also cause the generation of a large volume of toxic metal hydroxide sludge, which is also a health hazard due to its carcinogenic property [14]. This has resulted in disposal problems, as well as an increase in an ionic metal concentration of aluminum, specifically in treated water [15]. In comparison to inorganic coagulants, the organic/bio-coagulant of chitosan promises excellent properties and performances with additional values of being more economical, widely available, free of toxins, and biodegradable [16].

Presently, coagulation processes have been intensively studied covering different aspects such as the effect of different types of coagulants [17], the utilization of modified coagulants $[18,19]$, and the effect of process parameters such as $\mathrm{pH}[20,21]$ and dosages on water/wastewater treatment [21]. Some of the studies include the comparison between different Al-based inorganic coagulants performances such as between $\mathrm{ACH}$, alum, and PAC [20]. In the study, the effect of $\mathrm{pH}$ on the treatment of humic acid (HA) kaolin-synthetic water showed that the coagulants have good performance in acidic conditions [20]. Apart from that, a comparison has also been conducted between inorganic and organic coagulants such as PAC and chitosan, where the dosage and the methods of coagulant addition were investigated [22]. In another study, the application of cationic-grafted starch (St-G) and PAC in low-turbidity micro-polluted surface water has also demonstrated a successful reduction in PAC dosage, when PAC was utilized as the co-coagulant [23]. Even though promising achievements have been reported previously, the application of the improved coagulants to the industries was still quite limited. Industries are still bound to the traditional practice of utilizing common Al-based coagulants such as alum, $\mathrm{PAC}$, and $\mathrm{ACH}$ following a standard operation procedure, without properly evaluating the optimum type of coagulants and their optimum parameters that could be utilized. Therefore, a study providing an in-depth insight on application, comparison, and optimization of the different Al-based coagulants commonly utilized in the industries and possible transitioning to natural coagulants to meet drinking water standards is necessary to ensure an economical and sustainable approach could be implemented.

Thus, this work was thoroughly carried out with the aim of identifying the performance of the commonly used Al-based coagulations in the industries and comparing them with an abundantly available, low-cost organic coagulant, such as chitosan for surface water treatment sources with various turbidities, which were obtained from different places in Melaka, one of the states in Malaysia. Focusing on treating surface water is important and still relevant, as presently around 114 million people globally are still dependent on surface water as a drinking water source [24]. To the best of the authors' knowledge, there are very limited references available that have reported on the performance comparison between chitosan and different types of Al-based coagulants via one-factor-at-a-time (OFAT) and optimization methods. Although the investigated water samples were sourced from Malaysia, the study is believed applicable for surface waters with properties within the 
turbidity investigated. Commonly, surface water with similar properties as Malaysia's surface water can be found in countries sharing similar tropical climates with south-western and north-eastern monsoons. Surface water quality has been reported to have been linked with climate change [25]. For example, the amount of rainfall could affect the erosion of soil and transport of fine sediments from land, thus influencing the amount of suspended solids [26], sediment outputs [27], and contaminant metal fluxes [28] in the surface water.

In this study, coagulants of an organic type such as chitosan, and inorganic types such as alum, PAC, and $\mathrm{ACH}$ were compared based on their performances in producing the best water quality to meet the standard of national drinking water during the treatment of the raw surface water. The water quality parameters, namely turbidity, metals' residual concentrations detected in the water sample, were measured before and after the jar test to determine the effectiveness of these coagulants. Real raw water sources that are fed to water treatment plants (WTPs) were obtained from different rivers and dams having turbidity values of $25.6,130.3,225$, and 826.4 NTU and contain a different concentration of metals. Two different techniques of one-factor-at-a-time (OFAT) and optimization using response surface methodology (RSM) were implemented. Apart from determining the optimum condition to meet the standard of national drinking water, the dominant factors, interaction effects between input factors on the responses, and comparison between organic and inorganic coagulants performance were also investigated. The number of coagulant process parameters investigated included the categorical factor (type of coagulant) and numerical factors ( $\mathrm{pH}$ and coagulant dosage). The obtained results from the optimization were also compared with the conventional jar test (using OFAT method) to validate the proof-of-concept study. This has not been reported so far and could be highly beneficial for industrial usage. The mechanism of the coagulation/flocculation process upon using organic and inorganic chemicals was also identified and presented.

\section{Methodology}

\subsection{Samples of Raw Water}

Surface water samples from different local river sources in Melaka state, Malaysia, were supplied by the Syarikat Air Melaka Berhad (SAMB), a state government-linked company, which is responsible for water supply services in Melaka, Malaysia. The water samples were mainly taken from three districts in Melaka state to represent the water from each district available in Melaka. The studied samples were taken from Gadek I WTP and Gadek II WTP situated in the Alor Gajah district, from Kesang River situated in the Jasin district and from Gangsa River located in the Central Melaka district. All the samples were characterized immediately after they were received and kept at room temperature $\left(25^{\circ} \mathrm{C}\right)$. The information of the water source and its qualities are listed in Table 1. Initial characteristics of the raw water were identified by using the methods presented in Section 2.2. The national standard of drinking water quality parameters was also included in Table 1.

Table 1. Water samples and their characteristics.

\begin{tabular}{cccccc}
\hline Water Sample & $\mathbf{p H}$ & Turbidity (NTU) & Aluminum (mg/L) & Iron (mg/L) & Manganese (mg/L) \\
\hline Gadek II WTP & 6.63 & 25.6 & 0.11 & 0.14 & 0.06 \\
Kesang River & 6.80 & 130.3 & 8.28 & 2.83 & 0.09 \\
Gadek I WTP & 5.21 & 826.3 & 75.10 & 7.70 & 0.10 \\
Gangsa River & 6.68 & 225.0 & 13.70 & 3.32 & 0.096 \\
National standard of drinking & $6.5-9.00$ & 5.0 & 0.20 & 0.30 & 0.10 \\
water quality [29] & & & & \\
\hline
\end{tabular}




\subsection{Coagulant Materials and Preparation Method}

Coagulants and Preparations

Three different inorganic coagulants,-(1) aluminum sulfate (alum) supplied by See Sen Chemical Bhd., (2) polyaluminum chloride (PAC) supplied by CCM Usaha Kimia (M) Sdn. Bhd., and (3) polyaluminum chlorohydrate ( $\mathrm{ACH})$, supplied by Chemkimia Sdn. Bhd.-were used. The organic coagulant chitosan was purchased from Sciencefield Expertise PLT in a solid form. The purchased chitosan had a deacetylation degree of $85 \%$. Coagulants were prepared with concentrations ranging from 5, 10, 15, and $20 \mathrm{mg} / \mathrm{L}$. The concentration of the $\mathrm{Al}$ in $\mathrm{mg} \mathrm{Al} / \mathrm{L}$ was based on the $\mathrm{Al}$ strength (\%) as shown in Table 2. For the aqueous coagulant, the solution was prepared in a 1-L volumetric flask using distilled water. As for the solid coagulant, the magnetic stir was applied to achieve a homogeneous solution. Unlike other coagulants, $10 \mathrm{~mL}$ of $0.1 \mathrm{M}$ of hydrochloric acid $(\mathrm{HCl})$ was initially required in the preparation of chitosan solution. Chitosan was left in the $\mathrm{HCl}$ solution for $2 \mathrm{~h}$ to ensure a complete dissolution, which was then diluted with distilled water to prepare for $1 \mathrm{mg} / \mathrm{L}$ chitosan. $\mathrm{HCl}$ was chosen instead of acetic acid to ensure that no contaminant of organic matter from the acetic acid to the sample could occur. The purity of the coagulant samples is shown in Table 2.

Table 2. Coagulants' properties and grades.

\begin{tabular}{|c|c|c|c|c|c|c|c|c|}
\hline \multirow{2}{*}{ Coagulant } & \multirow{2}{*}{$\begin{array}{l}\text { Specific } \\
\text { Gravity }\end{array}$} & \multirow{2}{*}{ Purity (\%) } & \multicolumn{3}{|c|}{ Strength $(\%)$} & \multirow{2}{*}{ Chloride (\%) } & \multirow{2}{*}{ Grade } & \multirow{2}{*}{$\begin{array}{c}\text { Cost (Ringgit } \\
\text { Malaysia/Metric Ton) }\end{array}$} \\
\hline & & & $\mathrm{Al}_{2} \mathrm{O}_{3}$ & Al & Basicity & & & \\
\hline $\begin{array}{c}\text { Aluminum } \\
\text { sulfate (alum) }\end{array}$ & 1.31 & $26-28$ & 8 & 4 & 0 & - & Industry & $\begin{array}{c}330 \\
1900 *\end{array}$ \\
\hline $\begin{array}{l}\text { Polyaluminum } \\
\text { chloride (PAC) }\end{array}$ & 1.22 & 22 & 10 & 5.6 & 50 & $10-10.5^{*}$ & Industry & $\begin{array}{c}740 \\
10,590 *\end{array}$ \\
\hline $\begin{array}{l}\text { Aluminum } \\
\text { chlorohydrate } \\
(\mathrm{ACH})\end{array}$ & 1.35 & $30-60$ & $23-24$ & 12 & 82 & 7.9-8.4 & Industry & $\begin{array}{c}2350 \\
11,860 *\end{array}$ \\
\hline$\left[\begin{array}{c}\text { Chitosan } \\
\text { [OH }\end{array}\right]$ & - & 100 & - & - & - & - & $\begin{array}{l}\text { Laboratory, } \\
85 \% \text { DD, } \\
900 \mathrm{kDa}\end{array}$ & 5630 \\
\hline
\end{tabular}

* Typical values and costs referred from [7].

\subsection{Jar Test}

A jar test was conducted as a batch process and consisted of a multiple flocculator system of the Velps Scientica model VP-F105-A0108, from Italy. Initially, raw water from different sources was mixed homogeneously before it was poured into 1-L beakers of 4 units. Samples were then measured for $\mathrm{pH}$, turbidity, and residual concentrations, after which $\mathrm{Fe}, \mathrm{Mn}$, and $\mathrm{Al}$ were detected (these could impose risk to health and/or could cause chronic problems to drinking water utilities [30], if presence above the allowable limit in the drinking water). The allowable limits of $\mathrm{Fe}, \mathrm{Mn}$, and $\mathrm{Al}$ are presented in Table 1. The desired amount of coagulant was then added in the beakers followed by agitation at different mixing times and speeds: rapid mixing of $150 \mathrm{rpm}$ for $1 \mathrm{~min}$, and subsequent slow mixing of $35 \mathrm{rpm}$ for $15 \mathrm{~min}$. The floc formed was allowed to settle for $30 \mathrm{~min}$ after terminating the agitation. Finally, the sample was withdrawn from the surface of the supernatant using a micropipette to measure the final turbidity, and the $\mathrm{Fe}, \mathrm{Mn}$, and $\mathrm{Al}$ concentration. Throughout the test, hydrated lime was used to adjust the $\mathrm{pH}$ to $6.5-9.00$ as set by the national standard of drinking water quality [29]. 


\subsection{Analysis}

\subsubsection{Turbidity}

The measurement of turbidity was conducted using a HACH 2100AN Turbidimeter (HACH Company, Ames, IA, USA) with a 30-mL sample cell. This measurement was based on the light-transmitting properties of the water.

\subsubsection{Aluminum, Manganese, and Iron(III)}

A syringe was used to withdraw the sample from the surface of the supernatant and the presence for $\mathrm{Al}, \mathrm{Mn}$, and $\mathrm{Fe}$, and their concentrations were detected using an Atomic Absorption Spectrometer (AAS) from Perkin Elmer, AAnalyst 800 model.

\subsubsection{Response Surface Methodology (RSM)}

A two-factor central composite design (CCD) with 4 four replicates at the center point was used in this study to find the best coagulant and optimum conditions for the treatment process of the surface water (Design Expert version 6.0.10). The response surface methodology (RSM) indicated a total of forty-eight (48) runs were needed to complete this design. Raw water from the Gangsa River with a turbidity reading of $225 \mathrm{NTU}, \mathrm{pH}$ of 6.68, and metal concentrations of $13.700 \mathrm{mg} / \mathrm{L}$ of $\mathrm{Al}, 3.322 \mathrm{of} \mathrm{mg} / \mathrm{L} \mathrm{Fe}$, and $0.096 \mathrm{of} \mathrm{mg/L} \mathrm{Mn}$ was chosen (see Table 1). Different water composition was utilized throughout the study to ensure consistency in the coagulants' performances. In RSM, the important variables investigated consist of numerical and categorical factors, which represented by coagulant dosage (A), initial $\mathrm{pH}(\mathrm{B})$, and type of coagulant (C), respectively. The effects of these variables were investigated against surface water turbidity (NTU) and final concentration of $\mathrm{Al}, \mathrm{Fe}$, and $\mathrm{Mn}(\mathrm{mg} / \mathrm{L})$. The coagulant used for this design was alum, $\mathrm{PAC}, \mathrm{ACH}$, and chitosan, and the range and level set for this design was as shown in Table 3. For the $\mathrm{pH}$, hydrated lime was used to increase the $\mathrm{pH}$ while $\mathrm{HCl}$ was used to reduce the $\mathrm{pH}$.

Table 3. Range and level for RSM.

\begin{tabular}{ccccc}
\hline \multirow{2}{*}{ Categorial Factor } & Numerical Variable & \multicolumn{3}{c}{ Range and Level } \\
\cline { 3 - 5 } & & $\mathbf{- 1}$ & $\mathbf{0}$ & $\mathbf{1}$ \\
\hline \multirow{2}{*}{ C, Coagulant } & A, dosage $(\mathrm{mg} / \mathrm{L})$ & 5.00 & 17.50 & 30.00 \\
& B, initial pH & 6.39 & 7.39 & 8.39 \\
\hline
\end{tabular}

In the RSM study, all experimental data were analyzed and consistency in experimental and predicted responses were evaluated using a response surface regression procedure to fit a second-degree polynomial equation presented in Equation (1).

$$
Y=\beta_{0}+\sum_{i=1}^{k} \beta_{i} X_{i}+\sum_{i=1}^{k} \beta_{i i} X_{i}^{2}+\sum_{i=1}^{k-1} \sum_{j=1}^{k} \beta_{i j} X_{i} X_{j}+\varepsilon
$$

where $Y$ is the predicted response factor, $\beta$ is the model coefficient, $\beta_{0}$ is the intercept term, $\beta_{i}$ is the linear coefficient, $\beta_{i i}$ is the second order polynomial coefficient, $\beta_{i j}$ is the interaction term, and $X_{i}, X_{j}$ are the coded independent variables. The analysis of variance (ANOVA) was also carried out to understand the interactions between variables and responses, while the quality of the fit polynomial models was evaluated using coefficient of determination, $R^{2}$. Further analysis on the interactions between factors and variables were also carried out using perturbation plots and $3 \mathrm{D}$ response surface diagram. Other statistical analysis namely $F$-test and $p$-value with a 95\% confidence level were also utilized to evaluate the statistical significance of the model. 


\section{Results and Discussion}

\subsection{Effect of Different Turbidity Values}

Raw water turbidity of 25.6 NTU: Figure 1 presents the result of sample water treatment having different turbidity levels of 25.6, 130.3, and 826.3 NTU using both organic and inorganic coagulants. Overall, it was observed that at water turbidity of 25.6 NTU, all coagulants successfully met the standard for national drinking water below $5 \mathrm{NTU}$, at all dosages investigated from 5 to $20 \mathrm{mg} / \mathrm{L}$. For the low water turbidity, ACH was not tested as the coagulants of lower strength, namely alum and PAC demonstrated excellent performance in treating surface water to the national standard of drinking water. Furthermore, the high cost of $\mathrm{ACH}$ has hindered the use of this coagulant for low turbidity water especially when alum and PAC can perform the process well. The organic coagulant of chitosan showed that the highest turbidity removal was achieved at a coagulant dosage of $10 \mathrm{mg} / \mathrm{L}$, while the inorganic coagulants of alum and PAC at $15 \mathrm{mg} / \mathrm{L}$ (Figure 1a).
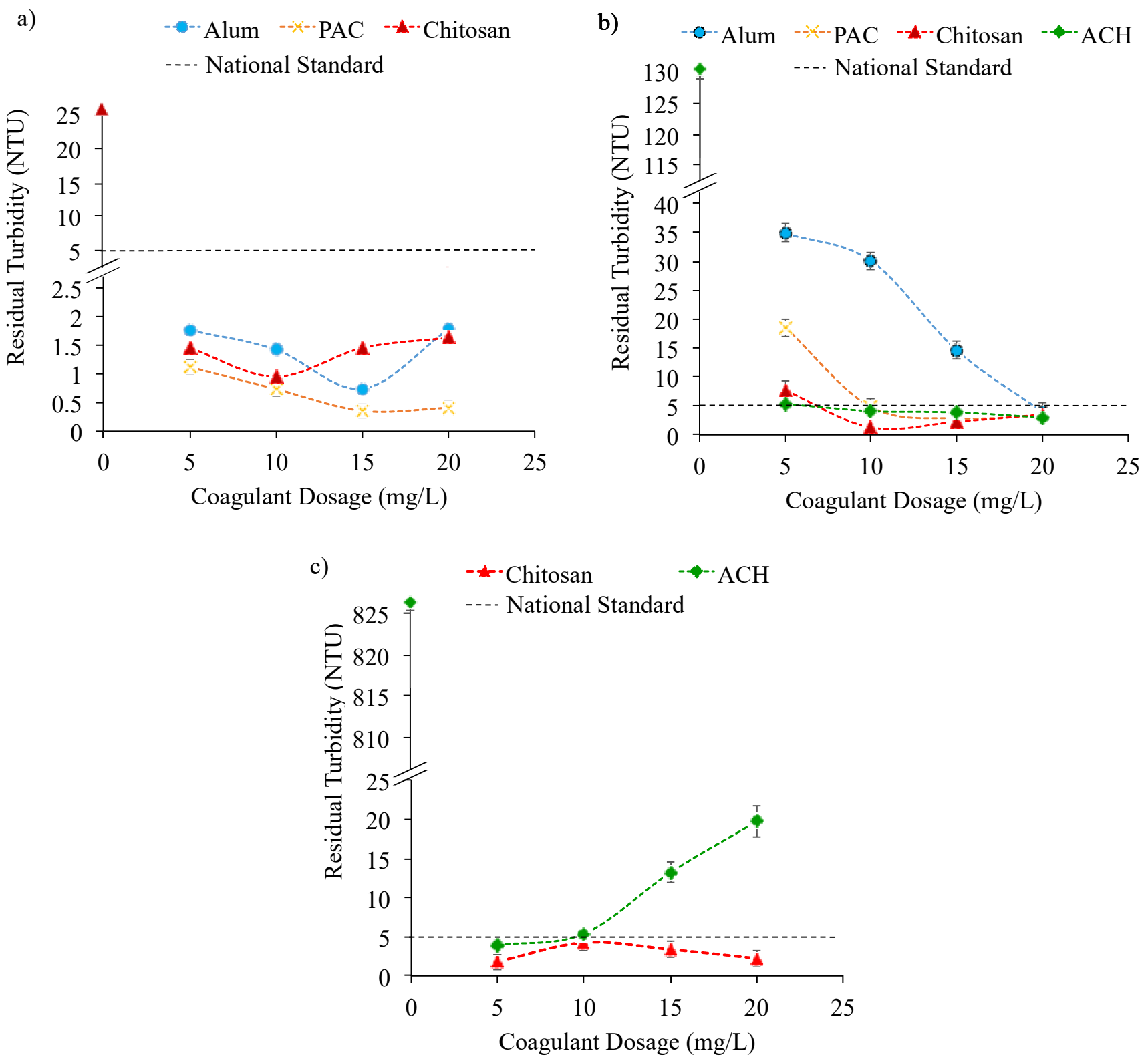

Figure 1. Residual turbidity versus coagulant dosage for different raw water initial turbidity of (a) 25.6 NTU (pH 6.63), (b) 130.3 NTU (pH 6.80), (c) 826.3 NTU (pH 5.21). 
Raw water turbidity of 130.3 NTU: At a higher turbidity water of 130.3 NTU, a low coagulant dosage of $5 \mathrm{mg} / \mathrm{L}$ did not reduce the water turbidity to the drinking water standard, especially for alum and PAC, which required higher dosages of 20 and $10 \mathrm{mg} / \mathrm{L}$, respectively (see Figure 1b). For PAC, a similar dosage of $15 \mathrm{mg} / \mathrm{L}$ as in the low turbidity water (25.6 NTU) was sufficient to achieve the highest turbidity removal. PAC was reported to have shown a better performance than alum. However, when PAC was compared with $\mathrm{ACH}, \mathrm{ACH}$ demonstrated better results (see Figure $1 \mathrm{~b}$ ). The difference in all the Albased coagulants' performances was based on the resultant $\mathrm{Al}$ species formed once the coagulants were added to water. Generally, $\mathrm{Al}^{3+}$ undergoes rapid hydrolysis reaction with water, and different $\mathrm{Al}$ species and $\mathrm{Al}$-hydroxide were formed including monomeric $\mathrm{Al}$ species $\left(\mathrm{Al}(\mathrm{OH})^{2+}, \mathrm{Al}(\mathrm{OH})_{2}{ }^{+}, \mathrm{Al}(\mathrm{OH})_{4}{ }^{-},\left(\mathrm{Al}_{2}(\mathrm{OH})_{2}{ }^{4+}, \mathrm{Al}_{3}(\mathrm{OH})_{4}{ }^{5+}\right)\right.$, medium polymerized $\mathrm{Al}$ species $\left(\mathrm{Al}_{13}\right)$, and/or high polymerized $\mathrm{Al}$ species $\left(\mathrm{Al}_{30}\right)$ [31]. From previous studies, coagulants with a high proportion of stable and high positive electrical charge of $\mathrm{Al}$ species such as $\mathrm{Al}_{13}$ and $\mathrm{Al}_{30}$ could remove contaminants efficiently [15,32]. $\mathrm{Al}_{13}$ was reported to have a highly charged cluster with seven positive charges that not only contributed to the effectiveness in the neutralization of contaminants but also acted as nucleate to form floc. Similarly, $\mathrm{Al}_{30}$ can effectively absorb negatively charged contaminants and precipitate easily due to its large molecular weight [31]. This phenomenon was found in accordance with the results obtained in this study, in which the coagulants' performance can be sequenced as alum $<\mathrm{PAC}<\mathrm{ACH}$. From Figure $1 \mathrm{~b}$, the drinking water standard of 5 NTU could be met at only $5 \mathrm{mg} / \mathrm{L}$ dosages for $\mathrm{ACH}$ compared to PAC and alum, which did not manage to comply with the standard at low coagulant dosage. The observation is also supported in previous studies [31,33]. Detailed discussion on the difference in the $\mathrm{Al}$ coagulation mechanisms is described and illustrated in Section 3.2.1 and Figure 2, respectively. Apart from the inorganic coagulants investigated, the tested organic coagulant of chitosan also showed a good performance in reducing water turbidity to below 5 NTU at a low coagulant dosage. From Figure 1a,b, the chitosan showed that the highest turbidity removal can be achieved at $10 \mathrm{mg} / \mathrm{L}$. The dosage was found consistent for turbidity water at 25.6 and 130.3 NTU. The less coagulant dosage requirement for chitosan compared to Al-based coagulants to achieve the drinking water standard is believed to be due to chitosan possessing high-charge density. Thus, a small amount of the dosage is already sufficient to destabilize particles. Similar results were also observed in the previous study [34-36], in which chitosan showed better effectiveness in a coagulation process at a lower dosage compared to the Al-based coagulants, with the additional advantages of being non-hazardous and more environmentally friendly [37,38].

Raw water turbidity of 826.3 NTU: As the chitosan and ACH demonstrated good performances in achieving residual turbidity as required for the drinking water standard, these coagulants were further tested at higher raw water turbidity of 826.3 NTU. From Figure 1c, even at high initial 826.3 NTU water' turbidity, chitosan could successfully maintain the residual turbidity of below 5 NTU at dosage below $10 \mathrm{mg} / \mathrm{L}$. Such a phenomenon may be explained based on the different $\mathrm{pH}$ values of the water samples taken from the WTP, because every turbidity recorded a different $\mathrm{pH}$ value. The highest turbidity of 826.3 NTU has a pH of 5.21 (see Table 1). Therefore, the good performance of chitosan even at high water turbidity of 826.3 NTU, may be contributed from the high acidity of the water sample. In an acidic condition $($ at $\mathrm{pH}<6$ ), chitosan usually demonstrates high zeta potential of more than $20 \mathrm{mV}$ [39]. At this condition, the amine $\left(\mathrm{NH}_{2}\right)$ functional groups present in chitosan are highly positively charged and they can effectively bind and bridge the negatively charged contaminants and colloidal materials. This could provide electrical neutrality at a low dosage via adsorption, charge neutralization, inter-particle bridging, and hydrophobic flocculation [37,40]. The presence of high number of protons in the solution at low $\mathrm{pH}$ conditions could protonate more amine groups of the chitosan molecule, thus, create more sites for adsorption of contaminants/metals. Moreover, flocs produced by chitosan coagulation were also reported to form and grow rapidly to a large size, thus easing the sedimentation process [38]. Therefore, such a phenomenon explained 
the high turbidity removal of chitosan even with a water sample with high turbidity of 826.3 NTU.

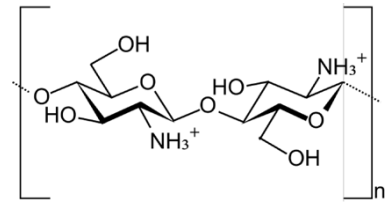

Chitosan

Al-based coagulant

$$
\begin{aligned}
& \text { Hydrolyzed species of } \\
& \text { Al-based coagulant } \\
& \left(\mathrm{Al}(\mathrm{OH})^{2+}, \mathrm{Al}_{2}(\mathrm{OH})_{2}{ }^{4+},\right. \\
& \left.\mathrm{Al}_{6}(\mathrm{OH})_{15}{ }^{3+}, \mathrm{Al}_{3}(\mathrm{OH})_{20}{ }^{4+}\right)
\end{aligned}
$$

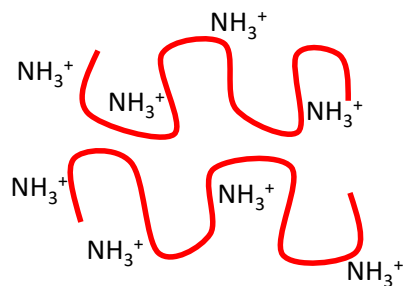

Charge Neutralization

Colloids

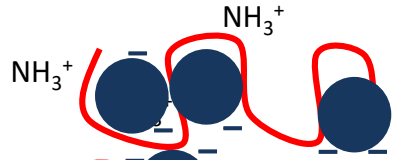

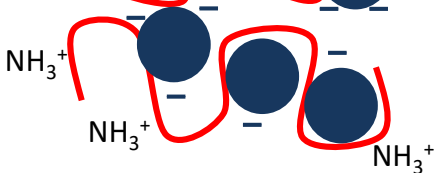

Polymer Bridging

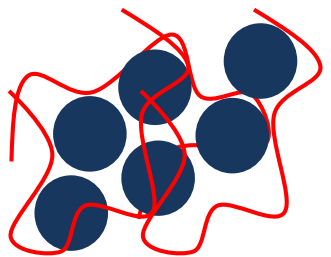

Charge Neutralization
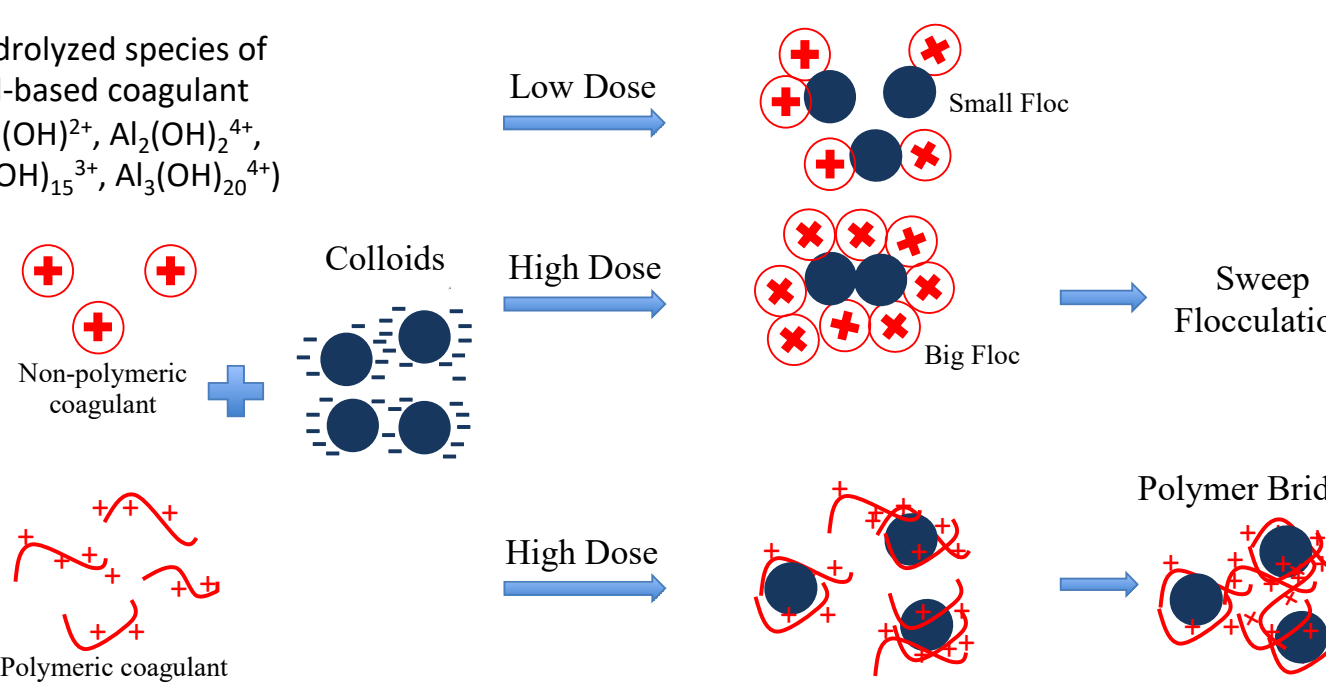

Flocculation

High Dose

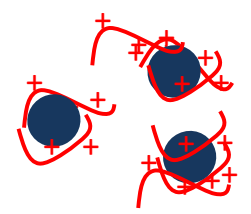

Polymer Bridging

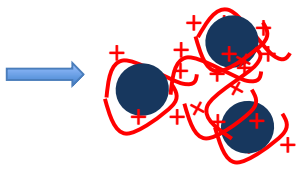

Figure 2. Illustration of coagulation-flocculation mechanisms of chitosan and Al-based coagulants (non-polymeric and polymeric coagulant).

Chitosan also shows good performance regardless of the coagulant dosage, which is believed to be due to the water sample's high acidity of $\mathrm{pH} 5.21$ that favors the chitosan coagulation process. The mechanism illustration of a coagulation-flocculation process using chitosan is also presented in Figure 2, which is further discussed in the later section of Section 3.2.1. In contrast, as for $\mathrm{ACH}$, at an increasing dosage, the turbidity removal performance of the coagulant reduced, which indicated that the coagulant performance worsened. In a low $\mathrm{pH}$ (acidic) sample, $\mathrm{ACH}$ was found to work best at a low coagulant dosage. At increasing coagulant dosages, charge reversal and possible destabilization of colloid particles may have occurred because of the possible occurrence of a significant reduction in $\mathrm{pH}$ of a sample when a high coagulant dosage was utilized [41]. In addition, the $\mathrm{pH}$ could affect the stabilization of a suspension. A similar result was also observed in the previous studies [41,42]. Meanwhile for the chitosan, charge reversal was not observed 
at an increasing dosage because at $\mathrm{pH}$ 5.21, only partial protonation may have occurred; thus, sufficient charge colloid and fine particles in the sample were available for attachment and polymer aggregation. As reported in other studies, chitosan could reach approximately $90 \%$ amine protonation at $\mathrm{pH} 4$, but reduces to $50 \%$ as the $\mathrm{pH}$ increases to $6[43,44]$.

\section{Coagulation-Flocculation Mechanism of Chitosan and Al-Based Coagulant}

From the results presented in the previous section, both inorganic and organic coagulants could meet the requirements of the national drinking water standard upon applying them at different coagulant dosages. However, the organic coagulant of chitosan demonstrated a low dosage requirement of only $10 \mathrm{mg} / \mathrm{L}$ compared to the Al-based coagulants investigated such as alum, PAC, and $\mathrm{ACH}$, which were found to be effective at a higher dosage at the condition of the raw water investigated. The differences in the coagulants performances can be described based on the coagulation-flocculation mechanisms, which are mainly influenced by the coagulant's molecular composition and properties. The illustration of the mechanisms is presented in Figure 2. Chitosan is a linear polysaccharide that consists of monomers of 2-amino-2-deoxy-D-glucose connected by $\alpha-1 \rightarrow 4$-linkages. The amino groups $\left(-\mathrm{NH}_{2}\right)$ at the $\mathrm{C}-2$ position can be protonated in acidic conditions resulting in a cationic property. Therefore, as chitosan is highly packed with positive charges, the coagulation mechanism worked by neutralizing the charge contaminants by stages, which consequently resulted in patches of neutralized micro-flocs. During the neutralization process, the repulsive interactions of the similarly-charged contaminants were reduced leading to destabilization of the contaminants [45]. This mechanism is followed by bridging the micro-flocs together through electrostatic binding with different loci available along the linear chain of the polysaccharide chitosan forming macro-flocs, which were then aggregated and settled [36]. The ability of chitosan to undergo charge neutralization and the interparticle bridging mechanisms with the contaminants contributed to the low requirement dosage of chitosan compared to the Al-based coagulant for effective coagulation process. However, it is important to note that at an increasing $\mathrm{pH}$ of a solution, different coagulation mechanisms of metal hydroxide may apply for chitosan. According to Blockx et al., (2018), chitosan started to precipitate at $\mathrm{pH}>7.5$ [39]. A similar study was also reported by Demir et al., (2020) on the flocculation of microalgae in chitosan, where effective flocculation was observed at $\mathrm{pH}<6.5$ based on the electrostatic interactions between chitosan and the negative cell surface of microalgae. On the other hand, a different mechanism was found upon increasing the $\mathrm{pH}$ with metal hydroxides whereby precipitation of chitosan occurred instead of flocculation [46].

In contrast, for the Al-based coagulants, the coagulation-flocculation process mainly evolved around charge neutralization mechanism. The contaminants need to be sufficiently large to form nuclei, especially for coagulants with a high fraction of monomeric $\mathrm{Al}$ species such as alum [47], as discussed in the previous Section 3.2. If an insufficient size of flocs was formed at a low dosage of the Al coagulant, no inter-particle bridging could happen, and thus no precipitation could occur through sweep-flocculation. This phenomenon usually occurred for coagulants with high monomeric Al species as the monomeric species is the most unstable species. As the dosing increases, the monomeric Al species could be transformed into more stable polymeric and colloidal species of $\mathrm{Al}_{13}$ and $\mathrm{Al}_{30}$ facilitating the growth of flocs via bridging [31]. Simultaneously, the complexation of contaminants with coagulant also occurred, reducing the negative charge of the contaminant. Consequently, the collision frequency and efficiency were favored, thus contributing to the growth of flocs [31]. The illustration of the mechanism can be seen in Figure 2. This is also true for polymeric coagulant, PAC, which undergoes a bridging mechanism. A sufficient amount of coagulant is needed for bridging to occur between the neutralized colloids [38] as illustrated in Figure 2. This phenomenon clearly reflects the result presented in Figure 1b, where at a water turbidity of 130.3 NTU, the increase in alum and PAC dosages significantly reduced the water turbidity. 


\subsection{Effect of Metals Removal in Treated Water}

\subsubsection{Raw Water Turbidity of 25.6 NTU}

Apart from the turbidity removal discussed in the previous section, the coagulants' performances in removing residual metal concentrations such as $\mathrm{Al}, \mathrm{Mn}$, and $\mathrm{Fe}$ in the treated water was also investigated to ensure that their limit complies with the national standard of drinking water at $\mathrm{Al}, 0.20 \mathrm{mg} / \mathrm{L}, \mathrm{Mn}, 0.10 \mathrm{mg} / \mathrm{L}$, and Fe, $0.30 \mathrm{mg} / \mathrm{L}$ [29]. Exceeding the allowable limits could impose hazards to human health, the environment, and affect the properties of the drinking water.

In the low water turbidity of $25.6 \mathrm{NTU}$, initial metal concentrations of $\mathrm{Al}, \mathrm{Mn}$, and $\mathrm{Fe}$ were found to be at $0.106,0.062$, and $0.142 \mathrm{mg} / \mathrm{L}$, which were already below the allowable limit of the national standard of drinking water (see Figure 3). Thus, for the 25.6 NTU water sample, only the effect of the Al-based coagulants' dosage on the residual $\mathrm{Al}$ concentration was investigated. From the results, after treating the water with Al-based coagulants, namely alum, PAC, and chitosan, there was no increase in residual $\mathrm{Al}$ concentrations; instead, the $\mathrm{Al}$ concentration was further reduced. Such a phenomenon indicated that the coagulation process was found effective at various coagulation dosages and process conditions of $\mathrm{pH}$ 6.63, in which flocs were readily formed and removed [33]. However, this phenomenon was only true for an alum coagulant concentration presence of up to $15 \mathrm{mg} / \mathrm{L}$, beyond which, the residual $\mathrm{Al}$ in the treated water increased more than its initial value of $0.106 \mathrm{mg} / \mathrm{L}$. At a high coagulant dosage, the hydrolysis of the alum reduced the final $\mathrm{pH}$ of the treated sample as shown in Figure $3 \mathrm{~b}$. This could possibly lead to the formation of some soluble $\mathrm{Al}$ species, thus increasing the residual $\mathrm{Al}$ concentration in the treated water [48]. A similar result was also observed in the previous reported studies [33,49].

a)

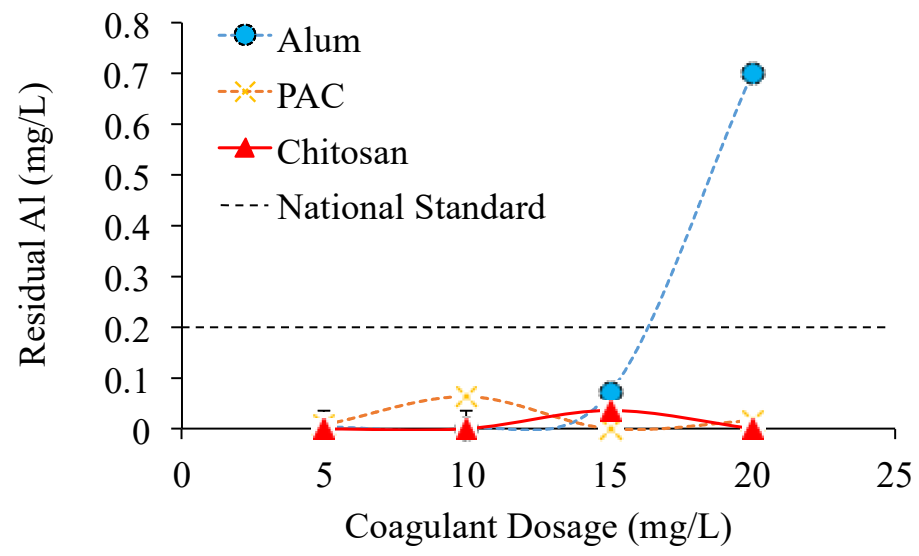

b)

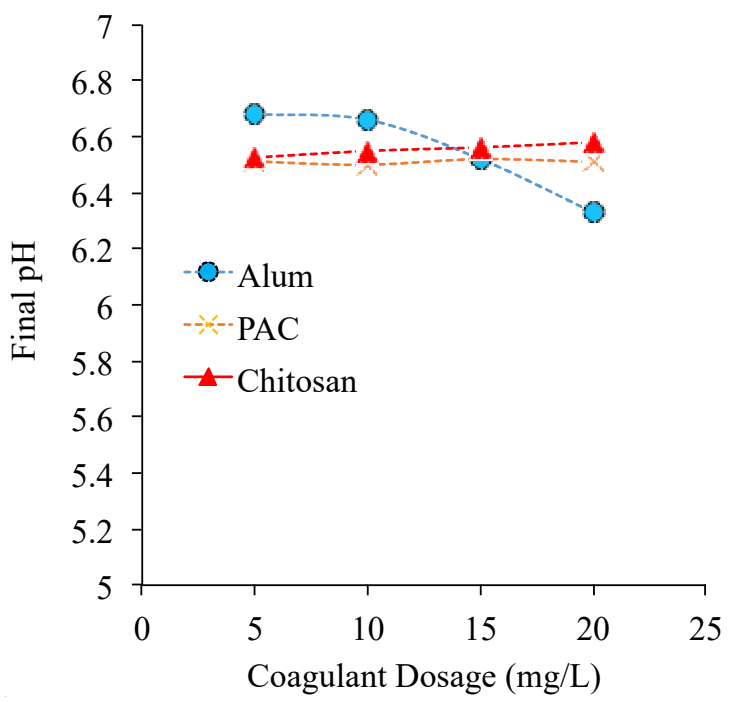

Figure 3. (a) Concentration of residual $\mathrm{Al}, \mathrm{Fe}$, and $\mathrm{Mn}$ in low water turbidity water using alum, PAC, and chitosan at dosages from 5 to $20 \mathrm{mg} / \mathrm{L}$, and (b) the final $\mathrm{pH}$ after coagulation process using alum, PAC, and chitosan.

\subsubsection{Raw Water Turbidity of 130.30 NTU}

Meanwhile, for samples with initial water turbidity of 130.30 NTU, the concentration of the residual $\mathrm{Al}$ and $\mathrm{Fe}$ are presented in Figure 4. The residual concentration of $\mathrm{Mn}$ was not discussed, as its concentration was already sufficiently low, at about $0.09 \mathrm{mg} / \mathrm{L}$ (below the standard of $0.10 \mathrm{mg} / \mathrm{L}$ ). For this water sample, the effect of using four different coagulants for the removal of metal concentrations was investigated namely alum, PAC, chitosan, and $\mathrm{ACH}$. Overall, Figure 4 shows that chitosan successfully reduced the concentration of $\mathrm{Al}$ to the standard of drinking water at all investigated dosages from 5 to $20 \mathrm{mg} / \mathrm{L}$. 
a)

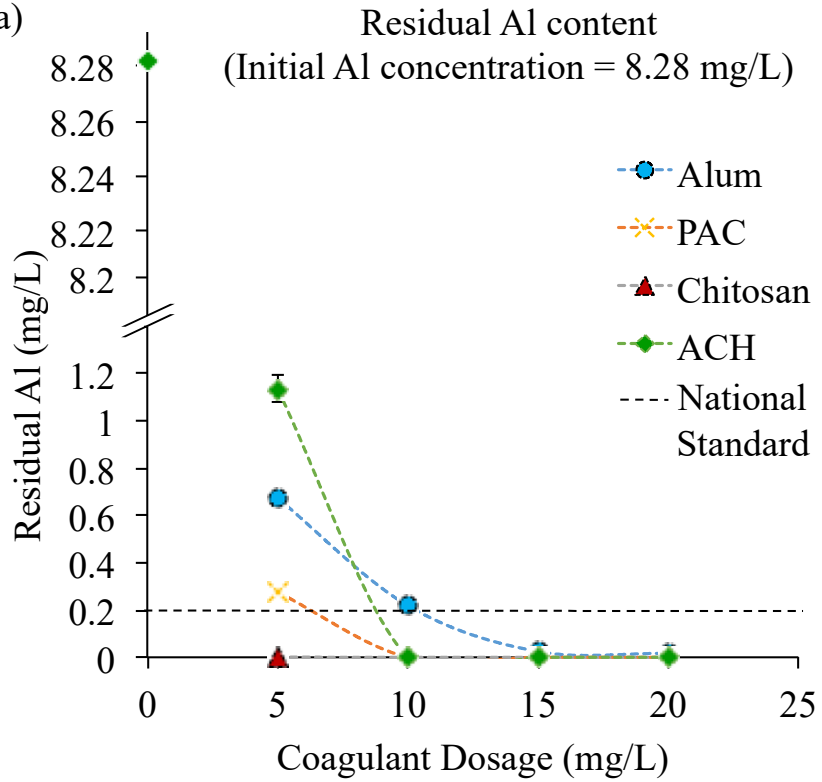

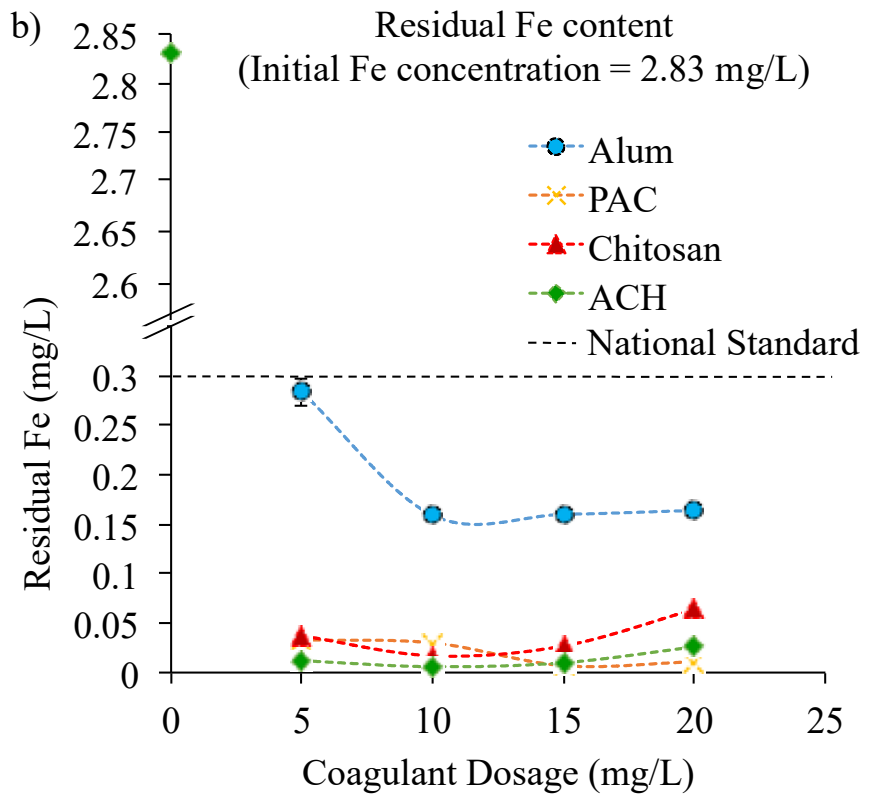

Figure 4. Concentration of (a) Al and (b) Fe in the treated water (initial water turbidity: 130.30/NTU, pH: 6.80; initial metal concentration: $\mathrm{Al}, 8.28 \mathrm{mg} / \mathrm{L} ; \mathrm{Mn}, 0.09 \mathrm{mg} / \mathrm{L} ; \mathrm{Fe}, 2.83 \mathrm{mg} / \mathrm{L}$; national standard of drinking water content; $\mathrm{Al}=0.20 \mathrm{mg} / \mathrm{L}$, $\mathrm{Mn}=0.10 \mathrm{mg} / \mathrm{L}$ and $\mathrm{Fe}=0.30 \mathrm{mg} / \mathrm{L})$.

In contrast, for the Al-based coagulants (alum, $\mathrm{PAC}$, and $\mathrm{ACH}$ ), a low dosage of $5 \mathrm{mg} / \mathrm{L}$ was found to be insufficient to reduce the $\mathrm{Al}$ concentration in the raw water sample to the allowable value of below $0.2 \mathrm{mg} / \mathrm{L}$. It was observed that a higher dosage of above $10 \mathrm{mg} / \mathrm{L}$ was required, except for the water treated with alum. The residual $\mathrm{Al}$ recorded in the alum-treated water sample was $0.22 \mathrm{mg} / \mathrm{L}$, slightly higher than the set standard of $0.20 \mathrm{mg} / \mathrm{L}$. This result was found to be consistent with the result obtained in the previous Section 3.1 on the turbidity removal and the coagulation-flocculation mechanism presented in Figure 2. The higher effectiveness of $\mathrm{ACH}$ and PAC compared to alum is because they both possessed higher basicity than alum $(0 \%$ basicity), with $0 \%$ basicity in alum indicating that alum has no-OH group in its structure that could increase its charge density for an effective contaminant removal [7]. Moreover, $\mathrm{ACH}$ and $\mathrm{PAC}$ also possess a high fraction of medium and high polymerized $\mathrm{Al}$ species of $\mathrm{Al}_{13}$ and $\mathrm{Al}_{30}$ that have low solubility and a large surface area to allow easy adsorption and co-precipitation of the contaminants [50]. This has resulted in the effective removal of Al (see Figure 4a). Kimura et al., (2013) reported that coagulant with the highest basicity demonstrated the lowest residual $\mathrm{Al}$ concentration in the final sample [50]. Generally, the increase in basicity can be correlated with the increase in the percentage of high polymerized $\mathrm{Al}$ species, $\mathrm{Al}_{30}$ in a coagulant [50]. These findings were also in accordance with the properties of the coagulants utilized in this study as presented in Table 1. Meanwhile, the alum demonstrated the effective removal of $\mathrm{Al}$ of up to $99 \%$ when the coagulant dosage was increased to more than $10 \mathrm{mg} / \mathrm{L}$ (see Figure $4 \mathrm{a}$ ).

In removing Fe in the water samples to the allowable limit $(<0.30 \mathrm{mg} / \mathrm{L})$, it was found that all coagulants including chitosan, $\mathrm{ACH}$, and PAC have performed the process well (see Figure $4 \mathrm{~b}$ ). In Fe removal using chitosan, the mechanism of retention involved a complex phenomenon of lump formation on the structure of chitosan with protonated groups of $-\mathrm{OH}_{2}{ }^{+}$and $-\mathrm{NH}_{3}{ }^{+}$. The strong coordination of Fe was formed with chitosan functional groups through surface adsorption [51]. A similar trend in $\mathrm{Al}$ removal was observed for $\mathrm{Fe}$ removal, which alum coagulant demonstrated as the least effective coagulant. Figure $4 \mathrm{~b}$ shows that at $5 \mathrm{mg} / \mathrm{L}$, the alum removal percentage was the lowest, at $90 \%(0.28 \mathrm{mg} / \mathrm{L})$, compared to the other coagulants with a removal percentage of more than $98 \%$. Moreover, at an increasing alum dosage of more than $5 \mathrm{mg} / \mathrm{L}$, its effectiveness in Fe removal could only reach up to $95 \%$. This is probably because alum has zero basicity properties and its 
lower fraction of the $\mathrm{Al}_{13}$ reduces alum's effective neutralization process of contaminants. For the other coagulants such as PAC, the highest removal of Fe is obtained at $15 \mathrm{mg} / \mathrm{L}$, while the $\mathrm{ACH}$ and chitosan are at $10 \mathrm{mg} / \mathrm{L}$.

\subsubsection{Raw Water Turbidity of 826.3 NTU}

For the treatment of the water sample with the highest water turbidity of $826.3 \mathrm{NTU}$, two of the best coagulants, namely chitosan and $\mathrm{ACH}$ at $10 \mathrm{mg} / \mathrm{L}$ were utilized, and dosage was determined based on the highest removal of metals obtained in the previous Section 3.2.2. As seen in Figure 5, at $10 \mathrm{mg} / \mathrm{L}$, both coagulants successfully reduced the concentration of all metals to the concentration permitted by the Ministry of Health, Malaysia $(\mathrm{MOH})$, consistent with the results obtained for turbidity removal of the water with low turbidity of 130.30 NTU. All metals were removed greater than $99 \%$. Such result is possibly obtained because the $\mathrm{ACH}$, a pre-hydrolyzed Al-based coagulant, and chitosan worked well in a wide $\mathrm{pH}$ range between 5.0 and 7.5 and at low coagulant dosage [52]. Therefore, despite the presence of higher metals concentration in the water samples with a turbidity of 826.3 NTU compared to other water samples with lower turbidity value, the $\mathrm{pH}$ of the water at 5.21 was still within the effective $\mathrm{pH}$ for $\mathrm{ACH}$ and chitosan coagulant efficacy. Previous studies have demonstrated that $\mathrm{pH}$ has significant effects on the coagulation process, in which $\mathrm{pH}$ influenced the hydrolysis, polymerization, and the resultant species of coagulants $[13,53]$. As for the Al-based coagulant, the hydrolysis of the coagulant was linked to the reduction coordination number of the Al. Therefore, different hydroxyl species of $\mathrm{Al}$ could be produced, which consequently affected the performance of the coagulant and the concentration of residual $\mathrm{Al}$ in the coagulation system [53].

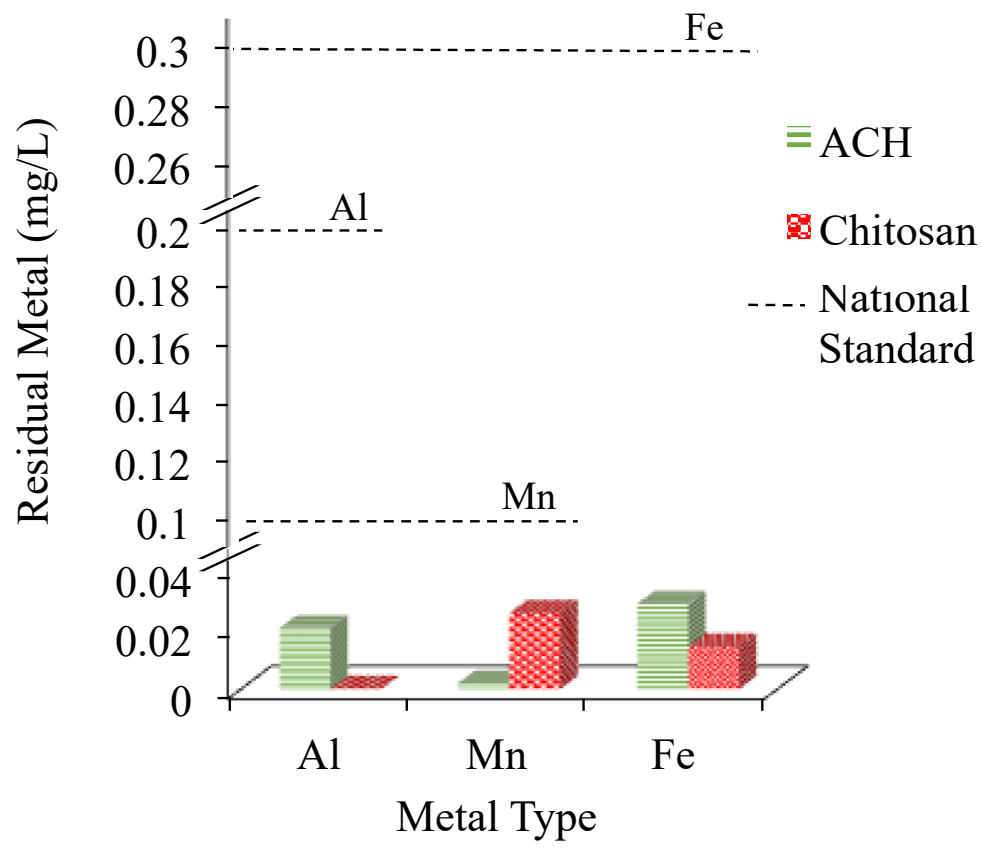

Figure 5. Residual concentration of $\mathrm{Al}, \mathrm{Mn}$, and $\mathrm{Fe}$ in treated water using $10 \mathrm{mg} / \mathrm{L}$ coagulant dosage of $\mathrm{ACH}$ and chitosan (initial water turbidity: $826.30 \mathrm{NTU}, \mathrm{pH}$ : 5.21; initial metal concentration: $\mathrm{Al}, 75.14 \mathrm{mg} / \mathrm{L} ; \mathrm{Mn}, 0.10 \mathrm{mg} / \mathrm{L} ; \mathrm{Fe}, 7.70 \mathrm{mg} / \mathrm{L}$; national standard of drinking water content; $\mathrm{Al}=0.20 \mathrm{mg} / \mathrm{L}, \mathrm{Mn}=0.10 \mathrm{mg} / \mathrm{L}$, and $\mathrm{Fe}=0.30 \mathrm{mg} / \mathrm{L}$ ).

Meanwhile, an effective reduction of the metal content in the water sample to the acceptable limit was successfully achieved upon using chitosan, regardless of their initial metal concentrations (see Figure 5). This result is found consistent with the results obtained in the turbidity removal using chitosan as discussed in Section 3.1 and also in the previous study reported utilizing chitosan for Fe and Mn removal [54]. In their study, Mn and Fe removal using chitosan was found to be dependent on the dosage of coagulant and 
$\mathrm{pH}$, where the metal removal increased with the increase in sample $\mathrm{pH}$ from 2.5 to 7 [54]. This may be attributed to the presence of a large number of protonated primary amino onto chitosan polymer chains that allow effective adsorption of metal ions. However, according to Babel et al., (2003), the protonation of primary amino groups is not the only factor contributing to this removal. The excellent metal-binding capacity of chitosan is also influenced by the flexible structure of polymer chains which is dependent on the $\mathrm{pH}$ of the solution [55]. In the other study reported by Guibal et al., (2004), the amino sites were found as the main reactive groups for metal ions adsorption, while hydroxyl groups may contribute to sorption only [56]. Even though both ACH and chitosan showed good performances, the utilization of chitosan as a coagulant is a step forward to eliminate the possibility of adding the $\mathrm{Al}$ compound that is abundantly present in the Al-based coagulant to the treated water.

\subsection{Jar Test Optimisation}

The response surface method (RSM) was also utilized in this study to further investigate the effect of factors including coagulant dosage, initial $\mathrm{pH}$ of water samples, and type of coagulants on the responses, which are the residual turbidity and metal concentration ( $\mathrm{Al}, \mathrm{Mn}, \mathrm{Fe})$. These include understanding interaction trends and behavior of the factors on the responses. Ranges and variables utilized in this section are included in Table 3. A complete set of the experimental design with two-factor CCD (four replicates) is presented in Supplementary Table S1, while the final model predictions presented based on the categorical factors are presented in Table S2. The prior table presents the actual and predicted responses from the interactions of factors, while the latter describes the consistencies between the experimental and predicted responses.

\subsubsection{ANOVA for Response Parameter}

Table 4 displays the results of the analysis of variance (ANOVA) of the developed models. From the ANOVA, it can be seen that all responses of turbidity, $\mathrm{Fe}$, and $\mathrm{Al}$, except $\mathrm{Mn}$, have significant relationships with the variable dosage, the initial $\mathrm{pH}$, and the type of coagulant. This was determined from the $F$-values and $p$-values generated from equations presented in Table S2. F-values obtained from the developed models were found to be greater than the critical $F$-value (2.004 at $95 \%$ significance) that was obtained from the standard distribution table with a degree of freedom equal to 14 and 33. Turbidity, Fe, and $\mathrm{Al}$ responses showed large $F$-values of 739.70, 14.12, and 63.34, respectively, which confirmed the sufficiency of the developed models. Ghafari et al., (2009) stated that a value for adequate precision of higher than four (4.0) indicated an adequate and desirable signal [57], which supported the findings. Similar results were also demonstrated by the $p$-values ( $p$-values $<0.05$ ), indicating that the model equations for turbidity, $\mathrm{Fe}$, and $\mathrm{Al}$ were statistically significant at the $95 \%$ confidence level. However, for $\mathrm{Mn}$, the model equation was not statistically significant. This was demonstrated by the low $F$-values of 1.18 and $p$-values $>0.05$ (see Table 4 ). Such values were observed probably due to the initial Mn concentration in the water sample was already low, around $0.096 \mathrm{mg} / \mathrm{L}$, lower than the requirement of the drinking water standard of $0.1 \mathrm{mg} / \mathrm{L}$. In general, coagulation of low pollutant loading, such as $\mathrm{Mn}$ in this study, is difficult as only a few flocs are available to form larger size flocs or colloids, but some may be of low density. Thus, good removal performance is hard to achieve since difficulty might occur in inducing collision between the colloids $[58,59]$. Such phenomenon may have resulted in the undesirable model equation.

Apart from the $F$-value and $p$-value, the lack-of-fit of the model regressions signifying the difference between experimental results and model predictions were also evaluated. From Table 4, the critical $F$-value for the Lack-of-Fit determined from the standard distribution table with degrees of freedom equal to 21 and 12 were found to be at 2.54 (95\% significance), higher than the $F$-values of the lack-of-fit for the quadratic model regressions. 
This indicated that the models are fit to be used to predict the responses in this study, which include turbidity and metal residual concentrations of Fe and Al.

Table 4. ANOVA results for the four responses including turbidity and residual concentration of Mn, $\mathrm{Fe}$, and $\mathrm{Al}$.

\begin{tabular}{ccccccc}
\hline Response & Source & ${ }^{\mathbf{a}} \mathbf{D F}$ & ${ }^{\mathbf{b}}$ SS & ${ }^{\mathbf{c}}$ MS & F-Value & Prob $>$ F \\
\hline \multirow{3}{*}{ Turbidity } & Regression & 14 & 5420.79 & 387.2 & 739.70 & $<0.0001$ \\
(NTU) & Residual & 33 & 17.27 & 0.52 & & \\
& Lack-of-fit & 21 & 3.45 & 0.64 & 2.01 & 0.11 \\
& Pure error & 12 & 3.82 & 0.32 & & \\
\hline & Regression & 14 & 0.01 & $9.39 \times 10^{-4}$ & 1.18 & 0.33 \\
$\mathrm{Mn}(\mathrm{g} / \mathrm{L})$ & Residual & 33 & 0.03 & $7.95 \times 10^{-4}$ & & \\
& Lack-of-fit & 21 & $6.73 \times 10^{-3}$ & $3.20 \times 10^{-4}$ & 0.2 & 0.99 \\
& Pure error & 12 & 0.02 & $1.63 \times 10^{-3}$ & & \\
\hline \multirow{3}{*}{$\mathrm{Fe}(\mathrm{g} / \mathrm{L})$} & Regression & 14 & 4.74 & 0.34 & 14.12 & $<0.0001$ \\
& Residual & 33 & 0.79 & 0.02 & & \\
& Lack-of-fit & 21 & 0.62 & 0.03 & 2.06 & 0.10 \\
& Pure error & 12 & 0.17 & 0.01 & & \\
\hline \multirow{2}{*}{$\mathrm{Al}(\mathrm{g} / \mathrm{L})$} & Regression & 14 & 108.92 & 7.78 & 63.34 & $<0.0001$ \\
& Residual & 33 & 4.05 & 0.12 & & \multirow{2}{*}{0.58} \\
& Lack-of-fit & 21 & 2.51 & 0.12 & 0.93 & \\
& Pure error & 12 & 1.55 & 0.13 & & \\
\hline
\end{tabular}

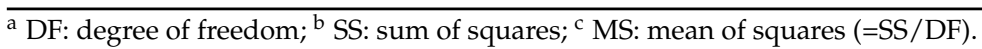

The validity of the model equations was also further analyzed using the $\mathrm{R}^{2}$ values. The results showed that the model predictions were in good agreement with the experimental values. The regression models could provide a reasonable fit for models containing a different number of independent variables and at making predictions, except for $\mathrm{Mn}$ $\left(R^{2}=0.33\right)$. Table 5 shows that the correlation coefficient, $R^{2}$ value for turbidity, and residual concentration of $\mathrm{Fe}$ and $\mathrm{Al}$ were at $0.99,0.86$, and 0.96 respectively, which were all in an acceptable range. The adequate precision values obtained were also $>4$, suggesting reliable experimental data were collected in the study. The $\mathrm{R}^{2}$ results further supported the $F$-value and $p$-value obtained, which were discussed in the previous paragraph.

Table 5. ANOVA analysis for quadratic model for each response.

\begin{tabular}{ccccc}
\hline Response & $\mathbf{R}^{\mathbf{2}}$ & Adjusted $\mathbf{R}^{\mathbf{2}}$ adj & Predicted $\mathbf{R}^{\mathbf{2}}$ & Adequate Precision \\
\hline Turbidity & 0.99 & 0.99 & 0.99 & 142.43 \\
Mn & 0.33 & 0.05 & -0.01 & 3.53 \\
Fe & 0.86 & 0.80 & 0.68 & 16.92 \\
Al & 0.96 & 0.95 & 0.93 & 41.25 \\
\hline
\end{tabular}

\subsubsection{Effects of Interaction Factors on the Responses}

Interaction factors for the two best coagulants, $\mathrm{ACH}$, and chitosan on the responses of turbidity and $\mathrm{Al}$ and $\mathrm{Fe}$ concentrations were also investigated using perturbation plots and 3D-response surface diagrams. However, the influence of factors on Mn concentration was not evaluated as Mn model regression was found to be insignificant, as discussed in Section 3.3.1.

Perturbation Plots: Figure 6 shows the perturbation plots comparing the responses' effect (turbidity and residual metal concentration) from the change of factors (coagulant dosage and $\mathrm{pH}$ ) over the range specified when chitosan and $\mathrm{ACH}$ were utilized as coagulants. A mid-point has been set as a reference point for all factors to investigate the sensitivity of the responses towards the input factors based on the steepness of the perturbation slope. Overall, Figure 6 demonstrates that the coagulant dosage plays an almost 
equal role as $\mathrm{pH}$ in determining the turbidity and residual metal removals from the water samples. This is indicated by an almost similar steepness obtained in the slopes of line $\mathrm{A}$ and line $\mathrm{B}$, especially for the turbidity and $\mathrm{Al}$ responses. However, coagulant dosage and $\mathrm{pH}$ exerted opposite effects on turbidity and metal removal. The turbidity and metal removal were reduced as the coagulant dosage increased but the opposite effect was seen with the increase in $\mathrm{pH}$. The reduction in turbidity and metal removal with the increased dosage could possibly be due to the occurrence of coagulant charge reversal at high dosage and particle restabilizing [32]. Meanwhile, for the effect of pH, Yang et al., (2010) previously reported that at low $\mathrm{pH}$ in a range of below 5 and up to 8 (weak alkalinity), effective turbidity, and metal removal could be observed. This happened because at this condition, the positive hydrolyzates such as $\mathrm{Al}(\mathrm{OH})^{2+}, \mathrm{Al}(\mathrm{OH})_{2}{ }^{+}, \mathrm{Al}_{2}(\mathrm{OH})_{2}{ }^{4+}, \mathrm{Al}_{3}(\mathrm{OH})_{4}{ }^{5+}$, high polymeric positive hydrolyzates, and $\mathrm{Al}(\mathrm{OH})_{3}$ are present. Therefore, the negative charged contaminants are easier to be neutralized by the positive hydrolyzates. The high polymeric hydrolyzates also have low solubility and large surface area, which could allow easy adsorption and co-precipitation of the contaminants. In their study, destabilization occurred at a higher $\mathrm{pH}$ because of the presence of a high fraction of soluble $\mathrm{Al}(\mathrm{OH})_{4}{ }^{-}$[20]. However, in relation to this study, the opposite trend was observed, both turbidity and metal removal was seen to occur effectively at a higher $\mathrm{pH}$ condition (see Figure $6 \mathrm{a}-\mathrm{c}$ ). This discrepancy may be explained due to the presence of a different distribution of $\mathrm{Al}$ speciation in the coagulants, which the $\mathrm{ACH}$ coagulant used in this study has a higher distribution of high polymerized $\mathrm{Al}$ species of $\mathrm{Al}_{30}$ compared to PAC coagulant utilized in [20]. A similar discussion can be found in the previous Section 3.2.2. With a high distribution of medium and high-polymerized $\mathrm{Al}$ species in the $\mathrm{ACH}$ coagulant compared to $\mathrm{PAC}$, the $\mathrm{ACH}$ coagulant could work efficiently at a high $\mathrm{pH}$ value. This finding explained the observed increasing turbidity and metal removal with increasing $\mathrm{pH}$ as shown in Figure $6 \mathrm{a}-\mathrm{c}$. These findings are the same as reported in previous studies $[50,60]$. These studies demonstrated that coagulants owing high basicity with more stable preformed $\mathrm{Al}$ species were found to work effectively at a higher $\mathrm{pH}$. However, it is important to note that, to achieve the drinking water standard, a balance between the coagulant dosage and the $\mathrm{pH}$ value is required.

Meanwhile, for the residual $\mathrm{Fe}$, the response shows a higher sensitivity towards changes in the coagulant dosage compared to $\mathrm{pH}$, especially for the $\mathrm{ACH}$ coagulant. This can be clearly seen in Figure 6b. Line A represents that the coagulant dosage displayed a steepness of several magnitudes higher than line B, which almost plateaued throughout the range investigated. The differences in the responses obtained with the change in the input factors were possible because of the different coagulation mechanisms that occurred at different process conditions. This was discussed in the previous Sections 3.1 and 3.2.2.

Nevertheless, when perturbation plots of chitosan were compared to $\mathrm{ACH}$, they have demonstrated lower response sensitivity towards the input factors $\mathrm{pH}$ and coagulant dosage). This is evaluated based on the steepness of the lines presented in Figure $6 \mathrm{~d}-\mathrm{f}$, which were less steep than the ACH (see Figure $6 \mathrm{a}-\mathrm{c}$ ). This difference in sensitivity of the responses to the changes in input factors may be due to the chitosan coagulation mechanism that did not depend on the hydrolysis of the coagulant, unlike the Al-based coagulants, which was described in Section 3.2.1. On the contrary to $\mathrm{ACH}$, the responses for $\mathrm{pH}$ when chitosan coagulant was utilized acted the other way round. At an initial $\mathrm{pH}$ of below 7.39, an increase in the coagulant dosage improved the performance of chitosan, wherein the turbidity and residual metals removal increased with dosage. However, at initial $\mathrm{pH}$ of above 7.39 , the trend was vice versa. The increase in chitosan dosage increased the residual turbidity of the samples. This can be explained by the precipitation of chitosan out of the solution as the $\mathrm{pH}$ reached > 7.5 [39]. According to Blockx et al., (2018), chitosan started to precipitate due to the partial deprotonation of amine groups, where the chitosan lost its positive charge. This contributed to the decreased in the chitosan solubility that consequently resulted in the precipitation of the chitosan [39]. Figure $6 \mathrm{~d}-\mathrm{f}$ shows that the performance of chitosan is highly dependent on the acidity of the water sample. As 
discussed in Section 3.2.1, the chitosan coagulation effectiveness is dependent on the protonation of the available amine functional groups in the chitosan molecular structure. Apart from that, as seen in Figure $6 \mathrm{~d}-\mathrm{f}$, the increased in coagulant dosage in acidic water sample condition also significantly reduced the turbidity of water sample below 5 NTU and the residual metals to the allowable limit, which supported the results obtained in the OFAT method. The technical and quantitative analysis from the comparison of the perturbation plots between $\mathrm{ACH}$ and chitosan provided clear evidence on how the responses reacted to the changes in the input factors when different coagulants were utilized.

3D Surface Response Diagram: Analysis of the optimization process was further carried out using the 3D response surface diagram presented in Figure $6 \mathrm{~g}-\mathrm{l}$. Overall, the $3 \mathrm{D}$ diagrams were found to be in accordance with the perturbation plots, in which the interaction effects of input factors on the responses can be clearly seen. Figure $6 \mathrm{~g}-\mathrm{i}$ shows that at low $\mathrm{ACH}$ dosage $<11 \mathrm{mg} / \mathrm{L}$, the $\mathrm{pH}$ of the water sample has a minimum effect on the performance. However, as the dosage increased, the effect of $\mathrm{pH}$ on the responses became significant, especially at a low $\mathrm{pH}$ value. Such a phenomenon was probably due to, at a higher dosage of coagulant, more hydrogen ions being produced from the hydrolysis of metal ions to form an aluminum hydroxide floc. The large number of hydrogen ions present in the water sample could react with the alkalinity of the water, rapidly decreasing the $\mathrm{pH}$, and thus could interrupt the removal process of turbidity and metals [52]. Generally, if the water sample has a low initial $\mathrm{pH}$ value, the alkalinity of the water may not be sufficient to react with the excess hydrogen ions from the high dosage of coagulants utilized; thus, the efficiency of the coagulation process could be significantly interrupted in reducing the turbidity level of the water sample (see Figure $6 \mathrm{~g}$ ). On the other hand, by having a high initial $\mathrm{pH}$ of the water sample, the high alkalinity of water could sufficiently react with the increasing amount of hydrogen ions to maintain the efficiency of the coagulation process. This can be clearly seen in Figure $6 \mathrm{~g}$, where turbidity removal was least affected by the changes in the coagulant dosage at a high $\mathrm{pH}$ value. The $\mathrm{ACH}$ coagulant was found to work optimally at a pH between 7.30-7.80 and dosage between $6.60-11.10 \mathrm{mg} / \mathrm{L}$. This result is also consistent with the ACH result obtained in OFAT method, in which the highest turbidity removal could be obtained at $10 \mathrm{mg} / \mathrm{L}$, within the optimum coagulant dosage determined by the RSM (6-11.10 mg/L).

Meanwhile, for chitosan, the optimization study showed that chitosan worked optimally in acidic conditions with a $\mathrm{pH}$ around 6.41-6.57, which was consistent with the perturbation plot and results obtained using the OFAT method. However, the optimum dosage of chitosan needed to achieve the drinking water standard determined from optimization (18.00-19.70 mg/L) was higher than the result obtained in the OFAT method $(10 \mathrm{mg} / \mathrm{L})$. Such results awee obtained due to the sufficiently lower $\mathrm{pH}$ of the water sample used in the OFAT (at $\mathrm{pH}$ of 5.21) compared to the studied $\mathrm{pH}$ utilized in the optimization of between 6.39 and 6.89. Previous studies reported that the protonation of $\mathrm{NH}_{2}$ in chitosan molecular structure could reach up to $90 \%$ at $\mathrm{pH} 4$ and regularly decreased to about $50 \%$ at $\mathrm{pH} 6[43,44]$. The reduction in $\mathrm{NH}_{2}$ protonation indicated that the positive charge on chitosan also decreased; thus, only fewer particles could be destabilized via the charge neutralization mechanism initiated by the chitosan for the turbidity and metal removal $[43,44]$. This explained the higher dosage of chitosan needed at a high initial pH (6.39-6.89) used in the optimization study compared to the low $\mathrm{pH}$ (5.21-6.80) of the water sample used in the OFAT study. Moreover, when chitosan was utilized as a coagulant in comparison to $\mathrm{ACH}$, the $\mathrm{pH}$ played a significant role in achieving the national standard of drinking water. 


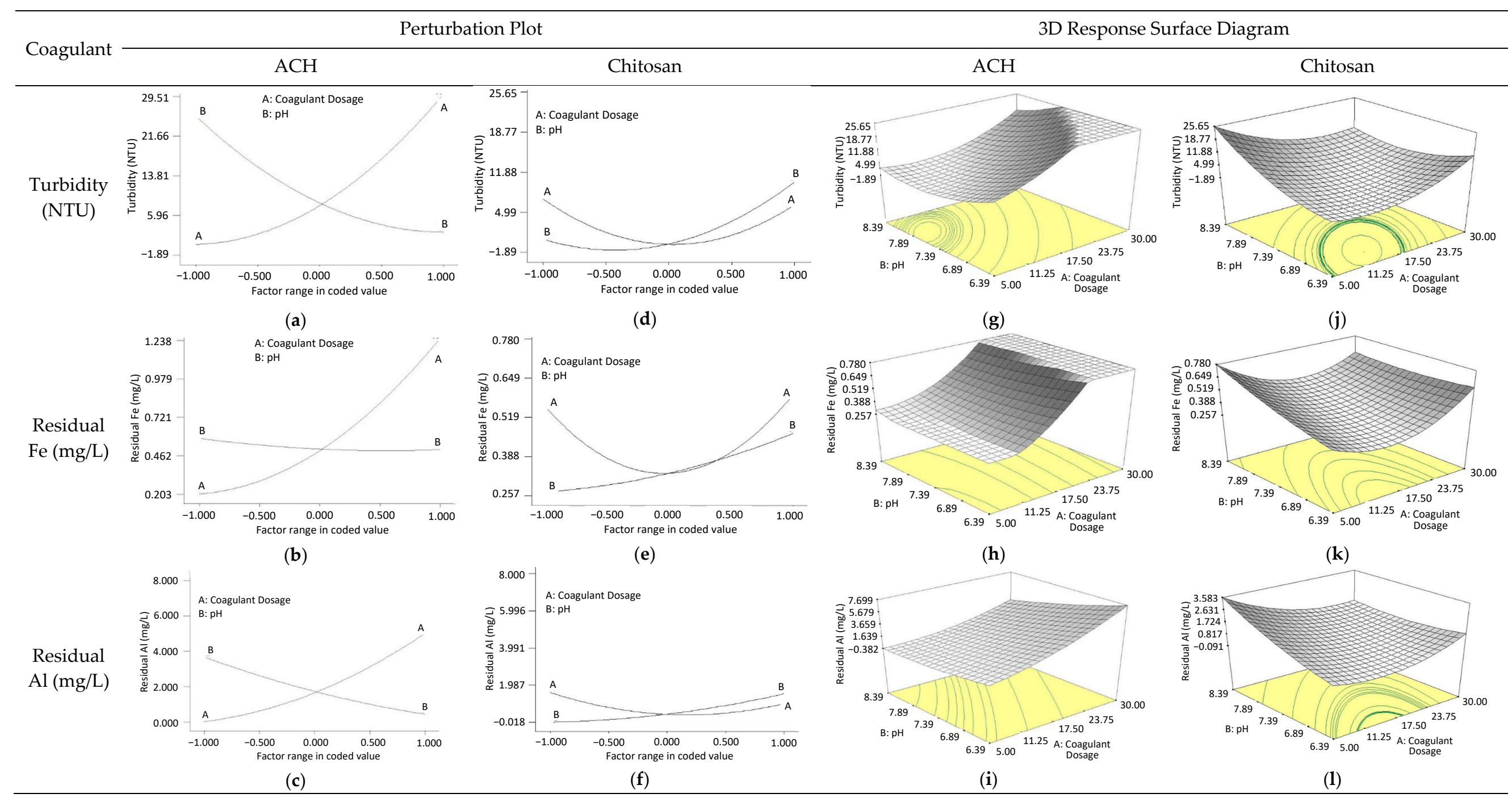

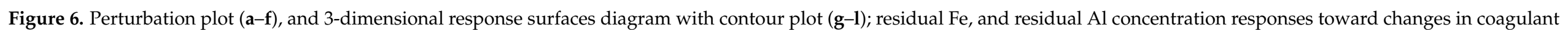
dosage and $\mathrm{pH}$ using $\mathrm{ACH}$ and chitosan as coagulants. 


\subsubsection{Model Validation and Comparison with the OFAT Method}

In order to validate the model and optimization process, an experimental run was carried out at the predicted optimum inputs generated by CCD, RSM. All the responses, namely turbidity, $\mathrm{Mn}, \mathrm{Fe}$, and $\mathrm{Al}$, were set to achieve below the national standard of drinking water at $5 \mathrm{NTU}$ (turbidity), $0.1(\mathrm{Mn}), 0.2(\mathrm{Al})$, and $0.3 \mathrm{mg} / \mathrm{L}(\mathrm{Fe})$. Meanwhile, the input factors-(i) coagulant dosage, (ii) initial $\mathrm{pH}$, and (iii) type of coagulants-were all set within the studied parameters as presented in Table 3. From the combination of categorical factor and numerical variables designed by $\mathrm{CCD}$ for the model validation, the coagulants of $\mathrm{ACH}$ and chitosan demonstrated a high desirability (D) of $\mathrm{D}=1$. The conducted experimental work performed at the optimal input conditions using $\mathrm{ACH}$ (categorical factor) at $\mathrm{pH} 7.40$ and dosage at $7.09 \mathrm{mg} / \mathrm{L}$ (numerical variable) was found to successfully reduce the turbidity and metal concentration of the treated water to the permissible limit. The turbidity removal was achieved up to $95 \%$, while $\mathrm{Mn}$ and $\mathrm{Al}$ recorded more than $99 \%$ removal, and finally Fe showed more than $90 \%$ removal. Similar results were also obtained when chitosan was utilized at the optimum pH of 6.41 and dosage of $18.63 \mathrm{mg} / \mathrm{L}$. The water sample was successfully treated to the national standard of drinking water.

\section{Conclusions}

In conclusion, the performance comparison between chitosan and the commonly used inorganic coagulants in treating some actual surface water samples from different WTPs to meet the national standard of drinking water were successfully investigated. Even though the application of chitosan, the non-toxic coagulant, and the Al-based coagulants, namely alum, $\mathrm{PAC}$, and $\mathrm{ACH}$, is well known in the water treatment process, a comprehensive comparison study between these coagulants was still limited. Overall, in this study, the one-factor-at-time (OFAT) method and the optimization results showed that the coagulants' physicochemical properties have a significant influence on the performance of the coagulants. This is reflected in the minimum requirement of the $\mathrm{ACH}$ and chitosan dosage $(10 \mathrm{mg} / \mathrm{L})$ in the removal of the turbidity and metal ions to achieve the standard of drinking water. ACH outperformed other Al-based coagulants due to its higher fraction of respective medium and high polymerized $\mathrm{Al}$ species of $\mathrm{A}_{13}$ and $\mathrm{Al}_{30}$, which allow easy adsorption and co-precipitation of contaminants. Meanwhile, for chitosan, the good performance in turbidity removal was due to its high positively charged structure. However, chitosan was found to work well at a low dosage in acidic conditions, while $\mathrm{ACH}$ worked well in basic conditions. As the $\mathrm{pH}$ of the water sample increases, a higher dosage of chitosan is required to meet the national standard of drinking water. This explained the high optimum chitosan dosage needed of $18.58 \pm 0.45 \mathrm{mg} / \mathrm{L}$ in the optimization study (pH: 6.39 and 6.89), compared to the OFAT method ( $\mathrm{pH}: 5.21$ and 6.8). As for ACH, the inorganic coagulant demonstrated a large range of working $\mathrm{pH}$ from 5.21 to 8.39 for a minimum $\mathrm{ACH}$ dosage of $10 \mathrm{mg} / \mathrm{L}$. Moreover, the study demonstrated that for $\mathrm{ACH}$, critical operational measures might be applied in contrast to chitosan. This is due to the perturbation plot and the $3 \mathrm{D}$ response surface diagram from the RSM optimization study, which demonstrated that all responses investigated were more sensitive to the input parameters when $\mathrm{ACH}$ coagulant was utilized. From this study, the application of RSM using CCD for jar test optimization showed that different coagulants have different optimum conditions to meet the national standard of drinking water, where the water sample conditions, such as $\mathrm{pH}$, are crucial in determining the type of coagulant utilized and its dosage. The use of alternative coagulants, namely chitosan, could give comparable performance as the inorganic $\mathrm{ACH}$ coagulant but at a different optimum condition. It can be also concluded that the RSM could assist in providing highly precise conditions of the coagulation parameters for water treatment and in-depth insight on the influence of the factors and their interaction on the responses. 
Supplementary Materials: The following are available online at https: / www.mdpi.com/article/ 10.3390/ijerph18179164/s1, Table S1: Central composite design (CCD) for experiment with actual and predicted responses of turbidity (NTU), residual concentration of $\mathrm{Mn}(\mathrm{mg} / \mathrm{L}), \mathrm{Fe}(\mathrm{mg} / \mathrm{L})$ and $\mathrm{Al}$ (mg/L); Table S2: Response surface models fitting correlating the responses (turbidity, concentration of $\mathrm{Mn}, \mathrm{Fe}$ and $\mathrm{Al}$ ), categorical (alum, $\mathrm{PAC}, \mathrm{ACH}$ and chitosan) and numerical factors (A: coagulant dosage; $\mathrm{B}$ : initial $\mathrm{pH}$ ) with their corresponding coefficient of the linear numerical factors, 2nd order numerical factors and two numerical interaction factors obtained by the regression analysis.

Author Contributions: Methodology, M.A.K., I.I.Y. and N.K.Z.; validation, R.R., I.I.Y. and N.K.Z.; formal analysis, M.A.K.; investigation, M.A.K.; resources, R.R., A.I.A.R. and N.K.Z.; data curation, N.K.Z., I.I.Y. and M.A.K.; writing—original draft preparation, M.A.K.; writing—review and editing, N.K.Z., I.I.Y. and R.R.; visualization, S.A.B.; supervision, R.R.; project administration, R.R.; funding acquisition, R.R. All authors have read and agreed to the published version of the manuscript.

Funding: The authors would like to acknowledge the financial support from the Ministry of Higher Education for Fundamental Research Grant Scheme (FRGS/2018/TK02/UKM/02/2) and Dana Impak Perdana Grant (DIP/2019/012) of UKM. In addition, the authors wish to thank UKM for the postdoctoral researcher scheme under Dana Modal Insan. Authors would also like acknowledge in-kind contribution and support by the Syarikat Air Melaka Berhad: Datuk Ir Mohd Khalid Nasir, Ir Shahirwan Arman Shah, Puan Rahimah Abdullah, Encik Mohd. Hafiz Abd. Rahman dan Puan Ermy Zulaika Jasmani.

Institutional Review Board Statement: Not applicable.

Informed Consent Statement: Not applicable.

Data Availability Statement: Not applicable.

Conflicts of Interest: The authors declare no conflict of interest.

\section{References}

1. Hameeteman, E. Future Water (in) Security: Facts, Figures, and Predictions; Water Congress: Bursa, Turkey, 2013.

2. Haan, T.Y.; Fen, C.S.; Radzi, M.F.; Ganasen, U. Comparative study for lake water remediation: Chemical coagulation and electrocoagulation. J. Kejuruter. SI 2018, 1, 81-87.

3. Hasan, H.A.; Muhammad, M.H.; Ismail, N.I. A review of biological drinking water treatment technologies for contaminants removal from polluted water resources. J. Water Process. Eng. 2020, 33, 101035. [CrossRef]

4. Ang, W.L.; Mohammad, A.W. State of the art and sustainability of natural coagulants in water and wastewater treatment. J. Clean. Prod. 2020, 262, 121267. [CrossRef]

5. Manda, I.K.M.; Chidya, R.C.G.; Saka, J.D.K.; Biswick, T.T. Comparative assessment of water treatment using polymeric and inorganic coagulants. Phys. Chem. Earth 2016, 93, 119-129. [CrossRef]

6. Temitope, A.A.; Samuel, L.N.; Abosede, O.O.; Toheeb, I.O.; Temitayo, O.O. Comparative Study on the Use of Moringa Oleifera as Natural Coagulant and Aluminium Sulphate in Restaurant Wastewater Treatment. J. Kejuruter. 2020, 32, $693-698$.

7. Gebbie, P. An Operator's Guide to Water Treatment Coagulants. In Proceedings of the 64th Annual Water Industry Engineers and Operators' Conference, Bendigo, Australia, 5-7 September 2006.

8. Brandt, M.J.; Johnson, K.M.; Elphiston, A.J.; Ratnayaka, D.D. Twort's Water Supply; Elsevier Ltd.: Amsterdam, The Netherlands, 2017; Chapter 12, pp. 513-552.

9. Bratby, J. Coagulation and Flocculation in Water and Wastewater Treatment; Water Intelligence Online: London, UK, 2006.

10. Prakash, N.B.; Sockan, V.; Jayakaran, P. Waste Water Treatment by Coagulation and Flocculation. Certif. Int. J. Eng. Sci. Innov. Technol. 2008, 9001, 2319-5967.

11. Kurniawan, S.B.; Abdullah, S.R.S.; Imron, M.F.; Said, N.S.M.; Ismail, N.I.; Hasan, H.A.; Othman, A.R.; Purwati, I.F. Challenges and Opportunities of Biocoagulant/Bioflocculant Application for Drinking Water and Wastewater Treatment and Its Potential for Sludge Recovery. Int. J. Environ. Res. Public Health 2020, 17, 9312. [CrossRef] [PubMed]

12. Lichtfouse, E.; Morin-Crini, N.; Fourmentin, M.; Zemmouri, H.; Nascimento, I.O.D.C. Chitosan for direct bioflocculation of wastewater. Env. Chem. Lett. 2019, 17, 1603-1621. [CrossRef]

13. Berube, D.; Dorea, C.C. Optimizing Alum Coagulation for Turbidity, Organics and Residual Al Reductions. Water Sci. Technol. Water Supply 2008, 8, 505-511. [CrossRef]

14. Salleh, S.N.A.M.; Zin, N.S.M.; Othman, N. A review of wastewater treatment using natural material and its potential as aid and composite coagulant. Sains Malays. 2019, 48, 155-164. [CrossRef]

15. Zouboulis, A.; Traskas, G.; Samaras, P. Comparison of Efficiency between Poly-aluminium Chloride and Aluminium Sulphate Coagulants during Full-scale Experiments in a Drinking Water Treatment Plant. Sep. Sci. Technol. 2007, 43, 1507-1519. [CrossRef] 
16. Tran, N.V.N.; Yu, Q.J.; Nguyen, T.P.; Wang, S.-L. Coagulation of Chitin Production Wastewater from Shrimp Scraps with By-Product Chitosan and Chemical Coagulants. Polymers 2020, 12, 607. [CrossRef]

17. Bolto, B.; Gregory, J. Organic Polyelectrolytes in Water Treatment. Water Res. 2007, 41, 2301-2342. [CrossRef]

18. Sun, Y.; Ren, M.; Zhu, C.; Xu, Y.; Zheng, H.; Xiao, X.; Wu, H.; Xia, T.; You, Z. UV-Initiated Graft Copolymerization of Cationic Chitosan-Based Flocculants for Treatment of Zinc Phosphate-Contaminated Wastewater. Ind. Eng. Chem. Res. 2016, 55, 10025-10035. [CrossRef]

19. Vigneshwaran, S.; Karthikeyan, P.; Sirajudheen, P.; Meenakshi, S. Optimization of sustainable chitosan/Moringa. oleifera as coagulant aid for the treatment of synthetic turbid water-A systemic study. Environ. Chem. Ecotoxicol. 2020, 2, 132-140. [CrossRef]

20. Yang, Z.L.; Gao, B.Y.; Yue, Q.Y.; Wang, Y. Effect of $\mathrm{pH}$ on the coagulation performance of Al-based coagulants and residual aluminum speciation during the treatment of humic acid-kaolin synthetic water. J. Hazard. Mater. 2010, 178, 596-603. [CrossRef] [PubMed]

21. Sun, Y.; Zhou, S.; Chiang, P.-C.; Shah, K.J. Evaluation and optimization of enhanced coagulation process: Water and energy nexus. Water-Energy Nexus 2019, 2, 25-36. [CrossRef]

22. Chen, F.; Liu, W.; Pan, Z.; Wang, Y.; Guo, X.; Sun, S.; Jia, R. Characteristics and mechanism of chitosan in flocculation for water coagulation in the Yellow River diversion reservoir. J. Water Process Eng. 2020, 34, 101191. [CrossRef]

23. Liu, Z.; Wei, H.; Li, A.; Yang, H. Enhanced coagulation of low-turbidity micro-polluted surface water: Properties and optimization. J. Environ. Manag. 2019, 233, 739-747. [CrossRef]

24. WHO. Drinking Water; World Health Organization: Geneva, Switzerland, 2019.

25. Whitehead, P.G.; Wilby, R.L.; Battarbee, R.W.; Kernan, M.; Wade, A.J. A review of the potential impacts of climate change on surface water quality. Hydrol. Sci. J. 2009, 54, 101-123. [CrossRef]

26. Lane, S.N.; Reid, S.C.; Tayefi, V.; Yu, D.; Hardy, R.J. Interactions between sediment delivery, channel change, climate change and flood risk in a temperate upland environment. Earth Surf. Process. Landf. 2007, 32, 429-446. [CrossRef]

27. Wilby, R.L.; Dalgleish, H.Y.; Foster, I.D.L. The impact of weather patterns on contemporary and historic catchment sediment yields. Earth Surf. Process. Landf. 1997, 22, 353-363. [CrossRef]

28. Longfield, S.A.; Macklin, M.G. The influence of recent environmental change on flooding and sediment fluxes in the Yorkshire Ouse basin. Hydrol. Process. 1999, 13, 1051-1066. [CrossRef]

29. Ministry of Health Malaysia. National Standard for Drinking Water Quality; Ministry of Health Malaysia: Kuala Lumpur, Malaysia, 2004.

30. Hasan, H.A.; Abdullah, S.R.S.; Kamarudin, S.K.; Kofli, N.T. Problems of ammonia and manganese in malaysian drinking water treatments. World Appl. Sci. J. 2011, 12, 1890-1896.

31. Yan, M.; Wang, D.; Ni, J.; Qu, J.; Chow, C.W.K.; Liu, H. Mechanism of natural organic matter removal by polyaluminum chloride: Effect of coagulant particle size and hydrolysis kinetics. Water Res. 2008, 42, 3361-3370. [CrossRef] [PubMed]

32. Malik, Q.H. Performance of alum and assorted coagulants in turbidity removal of muddy water. Appl. Water Sci. 2018, 8, 40. [CrossRef]

33. Krupinska, I. Aluminium drinking water treatment residuals and their toxic impact on human health. Molecules 2020, $25,641$. [CrossRef]

34. Maria, A.; Mayasari, E.; Irawati, U. Comparing the effectiveness of chitosan and conventional coagulants for coal wastewater treatment. IOP Conf. Ser. Mater. Sci. Eng. 2020, 980, 12077. [CrossRef]

35. Renault, F.; Sancey, B.; Badot, P.M.; Crini, G. Chitosan for coagulation/flocculation processes-an eco-friendly approach. Eur. Polym. J. 2009, 45, 48-1337. [CrossRef]

36. Bhalkaran, S.; Wilson, L.D. Investigation of Self-Assembly Processes for Chitosan-Based Coagulant-Flocculant Systems: A Mini-Review. Int. J. Mol. Sci. 2016, 17, 1662. [CrossRef]

37. Hesami, F.; Bina, B.; Ebrahimi, A. The effectiveness of chitosan as coagulant aid in turbidity removal from water. Int. J. Environ. Health Eng. 2014, 3, 8.

38. Ahmad, A.L.; Sumathi, S.; Hameed, B.H. Coagulation of residue oil and suspended solid in palm oil mill effluent by chitosan, alum and PAC. Chem. Eng. J. 2006, 118, 99-105. [CrossRef]

39. Blockx, J.; Verfaillie, A.; Thielemans, W.; Muylaert, K. Unravelling the Mechanism of Chitosan-Driven Flocculation of Microalgae in Seawater as a Function of Ph. ACS Sustain. Chem. Eng. 2018, 6, 11273-11279. [CrossRef]

40. Li, Q.; Kegley, L. Assessing the Effectiveness and Environmental Impacts of Using Natural Flocculants to Manage Turbidity; Oregon Department of Transportation Research Unit: Salem, MA, USA, 2005.

41. Saritha, V.; Srinivas, N.; Vuppala, N.V.S. Analysis and optimization of coagulation and flocculation process. Appl. Water Sci. 2017, 7, 451-460. [CrossRef]

42. Yukselen, M.A.; Gregory, J. The effect of rapid mixing on the break-up and re-formation of flocs. J. Chem. Technol. Biot. 2004, 79, 782-788. [CrossRef]

43. Cheng, W.P.; Chi, F.H.; Yu, R.F.; Lee, Y.C. Using Chitosan as a Coagulant in Recovery of Organic Matters from the Mash and Lauter Wastewater of Brewery. J. Polym. Environ. 2005, 13, 383-388. [CrossRef]

44. Domard, A.; Rinaudo, M.; Terrassin, C. Adsorption of chitosan and a quaternized derivative on kaolin. Appl. Polym. Sci. 1989, 38, 1799-1806. [CrossRef] 
45. Meraz, K.A.S.; Vargas, S.M.P.; Maldonado, J.T.L.; Bravo, J.M.C.; Guzman, M.T.O.; Maldonado, E.A.L. Eco-friendly innovation for nejayote coagulation-flocculation process using chitosan: Evaluation through Zeta $(\zeta)$ potential measurements. Chem. Eng. J. 2016, 284, 536-542. [CrossRef]

46. Demir, I.; Blockx, J.; Dague, E.; Guiraud, P.; Thielemans, W.; Muylaert, K.; Formosa-Dague, C. Nanoscale Evidence Unravels Microalgae Flocculation Mechanism Induced by Chitosan. ACS Appl. Bio Mater. 2020, 3, 8446-8459. [CrossRef]

47. Hu, C.Y.; Lo, S.L.; Hang, C.L.C.; Chen, F.L.; Wu, Y.D.; Ma, J.L. Treatment of highly turbid water using chitosan and aluminum salts. Sep. Pur. Technol. 2013, 104, 26-322. [CrossRef]

48. Chao, H.J.; Zhang, X.; Wang, W.; Li, D.; Ren, Y.; Kang, J.S.; Liu, D. Evaluation of carboxymethylpullulan-AlCl3 as a coagulant for water treatment: A case study with kaolin. Water Environ. Res. 2019, 1, 302-309.

49. Yang, Z.; Gao, B.; Cao, B.; Xu, W.; Yue, Q. Effect of $\mathrm{OH} / \mathrm{Al} 3 \mathrm{p}$ ratio on the coagulation behavior and residual aluminum speciation of polyaluminum chloride (PAC) in surface water treatment. Sep. Pur. Technol. 2011, 80, 59-66. [CrossRef]

50. Kimura, M.; Matsui, Y.; Kondo, K.; Ishikawa, T.B.; Matsushita, T.; Shirasaki, N. Minimizing residual aluminum concentration in treated water by tailoring properties of polyaluminum coagulants. Water Res. 2013, 47, 2075-2084. [CrossRef] [PubMed]

51. Nechita, P. Biological Activities and Application of Marine Polysaccharides; Shalaby, E., Ed.; IntechOpen: Cairo, Egypt, 2017. Available online: https:/ / www.intechopen.com/books/5412 (accessed on 23 August 2021).

52. Gebbie, P. Using Polyaluminium Coagulants In Water Treatment. In Proceedings of the 64th Annual Water Industry Engineers and Operators' Conference, All Seasons International Hotel, Bendigo, Australia, 5-6 September 2001.

53. Naceradska, J.; Pivokonska, L.; Pivokonsky, M. On the Importance of $\mathrm{pH}$ value in Coagulation. J. Water Supply Res. Technol.-Aqua 2019, 68, 222-230. [CrossRef]

54. Ali, M.E.A.; Aboelfadl, M.M.S.; Selim, A.M.; Khalil, H.F.; Elkady, G.M. Chitosan nanoparticles extracted from shrimp shells, application for removal of $\mathrm{Fe}(\mathrm{II})$ and $\mathrm{Mn}$ (II) from aqueous phases. Sep. Sci. Technol. 2018, 53, 2870-2881. [CrossRef]

55. Babel, S.; Kurniawan, T.A. Low-cost adsorbents for heavy metals uptake from contaminated water: A review. J. Hazard. Mater. B 2003, 97, 219-243. [CrossRef]

56. Guibal, E. Interactions of Metal Ions with Chitosan-Based Sorbents: A Review. Sep. Purif. Technol. 2004, 38, 43-74. [CrossRef]

57. Ghafiri, S.; Aziz, H.A.; Isa, M.H.; Zinatizadeh, A. Application of response surface methodology (RSM) tooptimize coagulationflocculation treatment of leachateusing poly-aluminum chloride (PAC) and alum. J. Hazard. Mater. 2009, 163, 650-656. [CrossRef]

58. Tang, X.; Zheng, H.; Teng, H.; Sun, Y.; Guo, J.; Xie, W.; Yang, Q.; Chen, W. Chemical coagulation process for the removal of heavy metals from water: A review. Desalination Water Treat. 2014, 57, 1733-1748. [CrossRef]

59. Basken, M.B.; Pala, A. Determination of arsenic removal efficiency by ferric ions using response surface methodology. J. Hazard. Mater. 2009, 166, 796-801. [CrossRef]

60. Yan, M.; Wang, D.; Yu, J.; Ni, J.; Edwards, M.; Qu, J. Enhanced coagulation with polyaluminium chlorides: Role of pH/Alkalinity and speciation. Chemosphere 2008, 71, 1665-1673. [CrossRef] [PubMed] 